\title{
PUB-5353
}

\section{Certification Plan Low-Level Waste}

\section{Hazardous Waste Handling Facility}

\section{Environment, Health and Safety Division}

\section{Lawrence Berkeley Laboratory}

Prepared for the U.S. Department of Energy under Contract No. DE-AC03-76SF00098

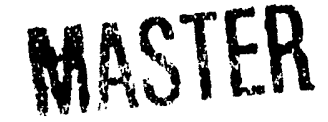




\section{Certification Plan Low-Level Waste Hazardous Waste Handling Facility}

\section{Environment, Health and Safety Division \\ Lawrence Berkeley Laboratory}

Prepared By:

Approved By:

Approved By:

Approved By:
Revision 0

June 30, 1992 achas as

Rich Albert, Procedures Writer

Environment Department

Environment, Health and Safety Division

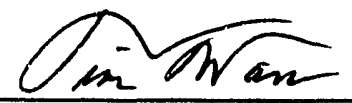

Tim Wan, Operations Unit Leader

Environment Department

Environment, Health and Safety Division

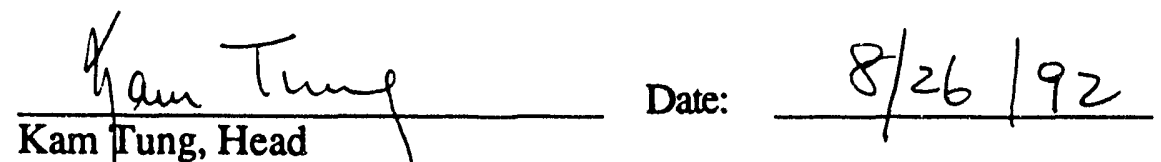

$$
8 / 26 / 92
$$

Date:
Environment Department

Environment, Health and Safety Division
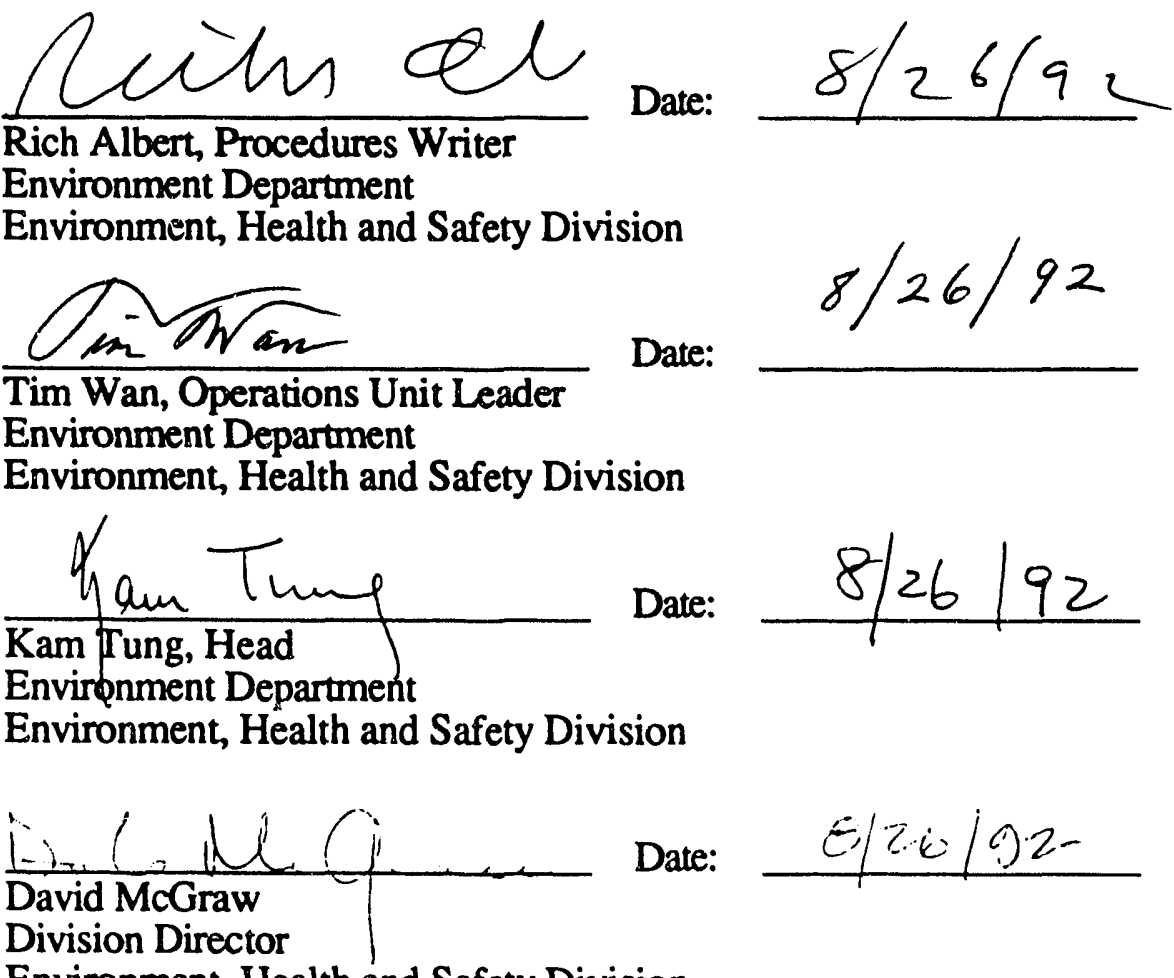

Date: $E / 2 i / 92-$

Environment, Health and Safety Division 


\section{Contents}

1 Introduction $1-1$

1.1 Purpose 1-1

1.2 Scope 1-1

1.3 Facility Description $1-2$

1.4 Facility Waste Management Strategy $1-6$

1.5 LLW Generation $1-10$

2 Organization and Responsibilities $\quad 2-1$

2.1 Description of Facility Organization 2-1

2.2 Duties and Responsibilities 2-1

2.3 Principal Interfaces $2-8$

3 Certification Methodology 3-1

3.1 Certification Process Description 3-1

3.2 LLW, Solid Compacted 3-18

3.3 LLW, Solid Noncompacted (Drums) 3-19

3.4 LLW, Solid Noncompacted (Wooden Boxes)

3.5 LLW, Induced Metals and Materials 3-21

3.6 LLW, Animal Carcasses $3-22$

3.7 LLW, Absorbed Tritium 3-23

3.8 LLW, Liquid Solidified 3-25

3.9 Methodology For Infrequent or Unforseen Waste Certification 3-27

3.10 Minimization 3-28

3.11 Segregation $3-29$

3.12 Onsite Treatment and Storage 3-29

3.13 Waste Characterization, Sampling, and Analysis 3-30

3.14 Waste Form Criteria 3-32

3.15 Waste Package Criteria 3-35

3.16 Containers $3-36$

3.17 Shipping $\quad 3-40$

3.18 Certification, Data Collection, and Record Keeping 3-41 


\section{Contents (Continued)}

4 Quality Assurance 4 4-1

4.1 QA Organization, Duties, and Responsibilities Summary 4-1

4.2 Summary of the Facility Quality Assurance Program 4-1

4.3 QA Program Index $\quad$ 4-8

5 References $\quad 5-1$

\section{Figures}

Figure 1-1. Location of LBL in Relation to its Surroundings 1-3

Figure 1-2. LBL Site Map Showing Location of the HWHF $1-4$

Figure 1-3. HWHF Site Plan $1-5$

Figure 2-1. Environment Department Organization Chart 2-2

Figure 2-2. Organizational Flow for LLW 2-3

Figure 3-1. Master Flow Chart for Low-Level Radioactive Waste at LBL, 3-2 with Governing Documents Listed

Figure 3-2. Characterization of Waste from RMMAs 3-4

Figure 3-3. Onsite Transfer of Waste to the HWHF 3-5

Figure 3-4. Application Process for SDARs 3-6

Figure 3-5. Documentation and Release of Radioactive Waste to Hanford- 3-7

Prior to Arrival of Truck that will Ship the Waste

Figure 3-6. Documentation and Release of Radioactive Waste to Hanford- 3-8

After Arrival of Truck that will Ship the Waste

Figure 4-1. EH\&S Organization

Tables

Table 4-1. NQA-1 Criteria and Relevant WM QAIMP Sections

\section{Appendices}

Appendix A. Waste Management Program Procedures $\quad$ A-1

Appendix B. Definitions $\quad$ B-1 


\section{Section 1: Introduction}

\subsection{Purpose}

The purpose of this plan is to describe the organization and methodology for the certification of low-level radioactive waste (LLW) handled in the Hazardous Waste Handling Facility (HWHF) at Lawrence Berkeley Laboratory (LBL). LLW is defined in Appendix B of this document and in the Westinghouse Hanford Company (WHC) Solid Waste Acceptance Criteria (WAC), Section 5 [1]. LLW that is co-contaminated with dangerous waste as defined in the Washington State Dangerous Waste Regulations, 173303-040 (18) [2] is considered radioactive mixed waste (RMW) and is addressed in the Radioactive Mixed Waste Certification Plan [3]. LLW is to be transferred to the WHC Hanford Site Central Waste Complex and Burial Grounds in Hanford, Washington.

The plan also incorporates the applicable elements of waste reduction, which include both up-front minimization and end-product treatment to reduce the volume and toxicity of the waste; segregation of the waste as it applies to certification; an executive summary of the Waste Management Quality Assurance Implementing Management Plan (QAIMP) for the HWHF (Section 4); and a list of the current and planned implementing procedures used in waste certification (Appendix A).

This plan provides guidance from the HWHF to waste generators, waste handlers, and the Waste Certification Specialist to enable them to conduct their activities and carry out their responsibilities in a manner that complies with the requirements of WHC-WAC [1]. Waste generators have the primary responsibility for the proper characterization of LLW. The Waste Certification Specialist verifies and certifies that LBL LLW is characterized, handled, and shipped in accordance with the requirements of WHC-WAC.

Certification is the governing process in which LBL personnel conduct their waste generating and waste handling activities in such a manner that the Waste Certification Specialist can verify that the requirements of WHC-WAC are met.

\subsection{Scope}

This LLW Certification Plan applies to that waste that is generated by LBL and becomes the responsibility of the HWHF. This plan is composed to meet the requirements 
found in WHC-WAC and follows the suggested outline provided by WHC in the letter of April 26, 1990, to Dr. R. H. Thomas, Occupational Health Division, LBL. LLW is defined in Department of Energy (DOE) Order 5820.2A [4]. Definitions are provided in Appendix B for convenience. LLW that also contains dangerous waste (RMW-LLW), as defined in the Washington State Department of Ecology Dangerous Waste Regulations [2], is addressed by the Radioactive Mixed Waste Certification Plan [3]. The certification process for transuranic (TRU) waste is addressed by the Transuranic Waste Certification Plan [5].

\subsection{Facility Description}

\subsubsection{Overall Facility}

LBL is located in the Oakland-Berkeley hills, adjacent to the Berkeley campus of the University of California. Figure 1-1 is a map of the Laboratory and surrounding area. LBL is a multipurpose national scientific laboratory, whose mission is to conduct forefront scientific research in several areas related to energy sciences, general sciences, and life sciences.

These research activities result in the generation of radioactive and hazardous wastes, as well as RMW.

\subsubsection{Hazardous Waste Handling Facility}

Hazardous waste, radioactive waste, and RMW are stored, packaged, and prepared for offsite transport at the HWHF. The HWHF is a Resource Conservation and Recovery Act (RCRA) facility and consists of several indoor and outdoor handling and storage areas. Activities performed at the HWHF consist primarily of consolidation, storage, and packaging of the waste for safe removal and transportation to a permanent offsite disposal facility. LBL has no waste disposal facilities. Figure 1-2 is the LBL site plan, showing the location of the HWHF. Figure 1-3 is a site plan of the HWHF, showing the location of the waste handling and storage areas. 


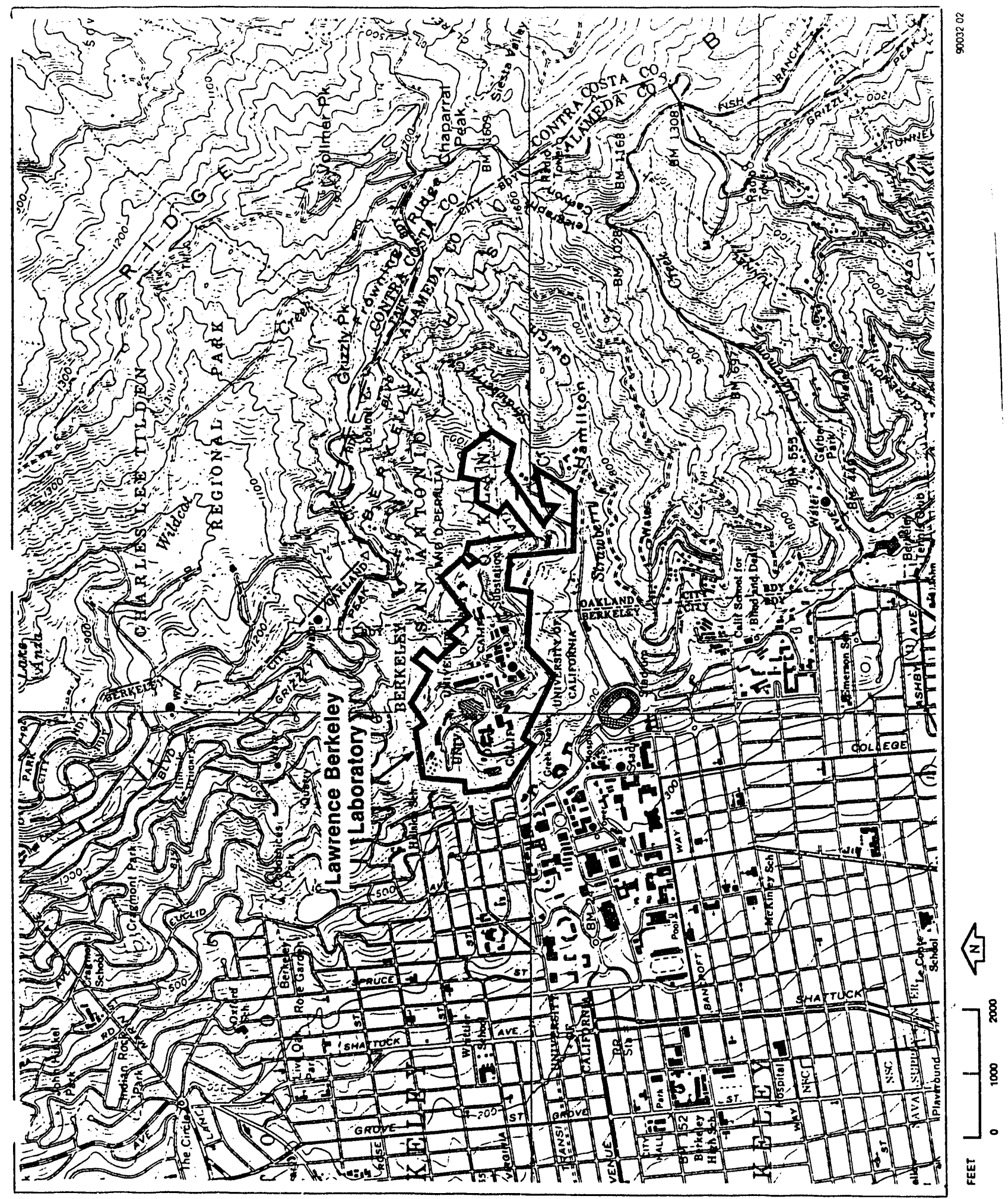

Figure 1-1. Location of LBL in relation to its surroundings 


\section{Lawrence Berkeley Laboratory Building Locations}

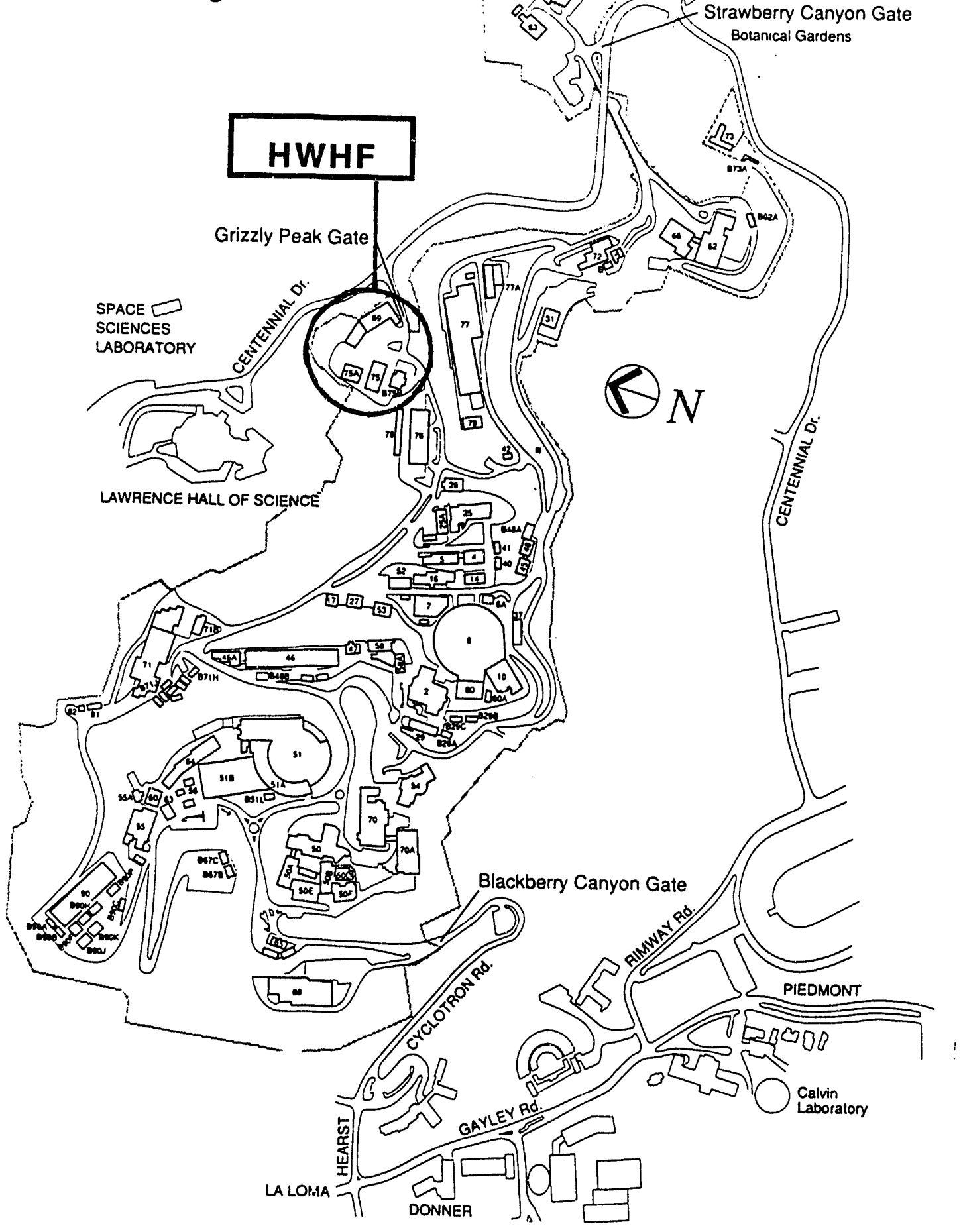

Figure 1-2. LBL site map, showing location of the HWHF 


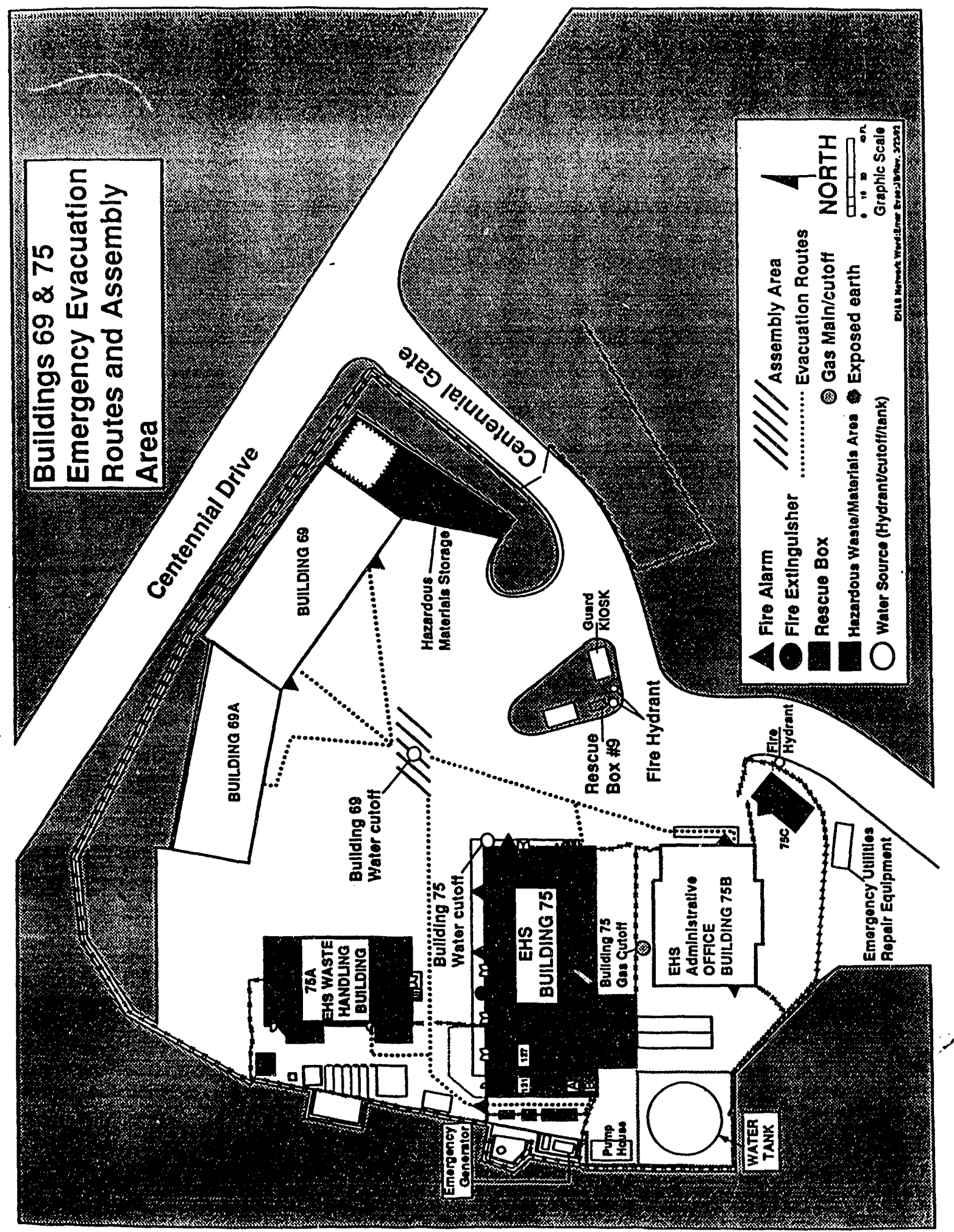

Figure 1-3. HWHF site plan 
LLW is managed at LBL in accordance with applicable U.S. DOE, U.S. Environmental Protection Agency (EPA), State of California, and Washington State regulations and is packaged and transported to the WHC disposal/storage site in accordance with U.S. Department of Transportation (DOT) regulations.

WHC determines whether each request for storage or disposal of LLW meets its requirements, and prepares and issues a Storage/Disposal Approval Record (SDAR).

A new HWHF is currently in the design phase and undergoing NEPAVEQA review. The new facility will consolidate separate waste-handling operations in one modern facility with enhanced safety and waste-containment functions. A Part B Permit Application is being processed by the California Environmental Protection Agency (CalEPA) to cover operations at the new facility and to close the existing one.

\subsection{Facility Waste Management Strategy}

The Environment, Health and Safety Division (EH\&S) is responsible for the preparation of the Waste Management Plan [6], which governs treatment, storage, and shipment of $\mathrm{LLW}$. Individual generators are responsible for the characterization of wastes, including LLW, in accordance with procedures established by EH\&S.

\subsubsection{References}

The LBL Waste Management Program meets the applicable guidance of the following:

- DOE Order 5820.2A, Radioactive Waste Management [4]

- EPA Regulations, Title 40 CFR [7]

- DOT regulations, Title 49 CFR 171-173 [8]

- Washington State, Dangerous Waste Regulations, Washington Administrative Code, Chapter 173-303 [2]

- State of California, Title 22, California Administrative Code, Chapter 30 [9] 
- Hanford Site Radioactive Solid Waste Acceptanci Criteria [1]

The Waste Management Program at LBL is implemented through the following documents, in addition to this Waste Certification Plan:

- LBL Health and Safety Manual, PUB-3000 [10]

- Waste Management procedures (listed in Appendix A)

- Waste Management Plan [6]

- Hazardous Waste Management Program, General Policy Statement, EH\&S Procedure 800

- Guidelines for Generators of Hazardous Chemical Waste at LBL and Guidelines for Generators of Radioactive and Mixed Waste at LBL [11] (hereinafter called the Guidelines for Generators)

-Waste Minimization and Pollution Prevention Awareness Plan [12]

- Waste Management Quality Assurance Implementing Management Plan [13]

\subsubsection{Summary of Waste Minimization, Segregation, Certification, Packaging, and} Shipping Activities

Minimization. The Waste Minimization and Pollution Prevention Awareness Plan [12] provides the policy, strategy, objectives, and goals for waste minimization at LBL.

Segregation. Segregation activities include specific separation and storage instructions contained in the Guidelines for Generators [11] and detailed in specific waste stream procedures, as listed in Appendix A. Actions currently practiced at LBL to achieve waste segregation include

- handling radioactive wastes separately from all other wastes

- using good housekeeping in hoods, glove boxes, and laboratories 
- accumulating radioactive wastes in separate, labeled, specially designated containers (e.g., ice cream cartons or waste sacks in garbage cans)

- transporting radioactive wastes separately from other types of waste

- storing radioactive waste in separate areas at the HWHF

- keeping sharp objects (e.g., hypodermic needles, scalpels) in separate protective containers.

Certification. This LLW Certification Plan is established by the HV/HF to demonstrate compliance with WHC-WAC [1] for LLW. The processes fior identifying, packaging, labeling, marking, and documenting LLW are identified in Section 3 of this LLW Certification Plan.

LBL requires all waste generators to attend training courses that support the detailed implementation of waste handling, sampling, and analysis activities sufficient to assure certification. The Guidelines for Generators [11] has also been issued for use.

Packaging. Waste packaging criteria are identified in Section 3.15 for each waste stream. LBL practices for packaging of LLW include

- packaging noncompactable waste separately

- keeping sharp objects (hypodermic needles, scalpels) in separate protective containers

- inspecting shipping containers upon receipt to assure that the containers are in acceptable condition and properly marked, and after packaging to assure marking, labeling, and closure are adequate, according to Quality Control (QC) inspection procedures

- conducting inspection or surveillance during packaging operations to assure that the waste acceptance criteria are being met 
Shipping. Shipping requirements are identified in Section 3.17. LBL shipping practices include

- transporting $\mathrm{LWW}$ separately in containers that meet all applicable regulations

- inspecting all shipping containers for integrity and proper marking and labeling

- inspecting the loaded vehicle to ensure that it is properly blocked and braced, properly placarded, and meets dose-rate and contamination limits

- complying with DOT radioactive materials transportation regulations (49 CFR) and WHC-WAC [1].

\subsubsection{Waste Disposal QA Program Summary}

A summary of the Waste Management QAIMP [13] requirements for LLW certification is presented in Section 4. The following are some important requirements of the QAIMP.

- Regular inspections of the HWHF and the stored waste are performed by EH\&S personnel.

- Internal audits are conducted By LBL's Office of Assessment And Assurance on a two- or three-year basis.

- DOE external audits are done periodically.

- Functional audits of the Waste Management program by each of the other EH\&S Departments (Health, Safety) are done at least annually, depending on the findings of previous audits. The following groups provide annual functional audits of the Waste Management Program:

- Health Department: Industrial Hygiene Group, Radiation Assessment Group

- Safety Department: Occupational Safety Group, Fire Department's Prevention Unit (the Fire Department is part of the Safety Department) 
- Waste disposal personnel periodically review waste packaging, storage, and disposal requirements, including those stated in WHC-WAC [1] and other governing documents.

- Waste disposal personnel periodically review the LBL Waste Management Plan [6] and DOE Order 5820.2A [4].

\subsection{LLW Generation}

LLW is generated by many divisions at LBL. These include the Materials Sciences, Chemical Sciences, Accelerator and Fusion Research, Energy and Environment, and Biology and Medicine Divisions. Currently the LLW streams are identified, based on the following forms and characteristics:

- Solid compacted, consisting of dry laboratory wastes (plastic, rubber, paper, glass, and wood shavings) contaminated with long-lived radioisotopes.

- Solid noncompacted (drums), consisting of large solid contaminated objects.

- Solid noncompacted (wooden boxes), consisting of solid contaminated items too large to fit in a 55-gallon drum.

- Induced metals, consisting of nonhazardous metal waste made radioactive by bombardment with neutrons or charged particles produced by LBL accelerators.

- Animal carcasses, consisting of animal carcasses or tissues contaminated with radioisotopes.

- Absorbed tritium, consisting of HTO absorbed onto silica gel.

- Solidified liquid, consisting of research laboratory solutions solidified with portland cement and diatomaceous earth. 


\section{Section 2: Organization and Responsibilities}

\subsection{Description of Facility Organization}

The Environment Department of the Environment, Health, and Safety Division (EH\&S) has the responsibility for management of LLW at LBL. Within the Environment Department, the Operations Unit is responsible for handling and shipping LLW. Figure 21 shows the Environment Department organization, and Figure 2-2 shows the organizational flow for these wastes. The Waste Management Plan [6] defines the minimum standards of operation for the HWHF.

\subsection{Duties and Responsibilities}

This section lists positions responsible for the management and handling of LLW, with the responsibilities for each job title. Quality assurance (QA) responsibilities are listed where relevant. Additional responsibilities are listed in Section 4, Quality Assurance.

\subsubsection{Division Director, Environment, Health and Safety Division}

- Has overall responsibility for environment, health, and safety issues at LBL.

- Assures the resources necessary to conduct HWHF operations in a safe manner.

- Has overall responsibility for implementation of the Waste Management QAIMP [13] at the HWHF.

- Reviews and approves the Waste Management QAIMP and revisions.

- Approves Waste Management Program procedures.

\subsubsection{Department Head, Environment Department}

- Is responsible for directing and monitoring all HWHF operations. 


\section{Lawrence Berkeley Laboratory}

\section{Environment Department}

Organization

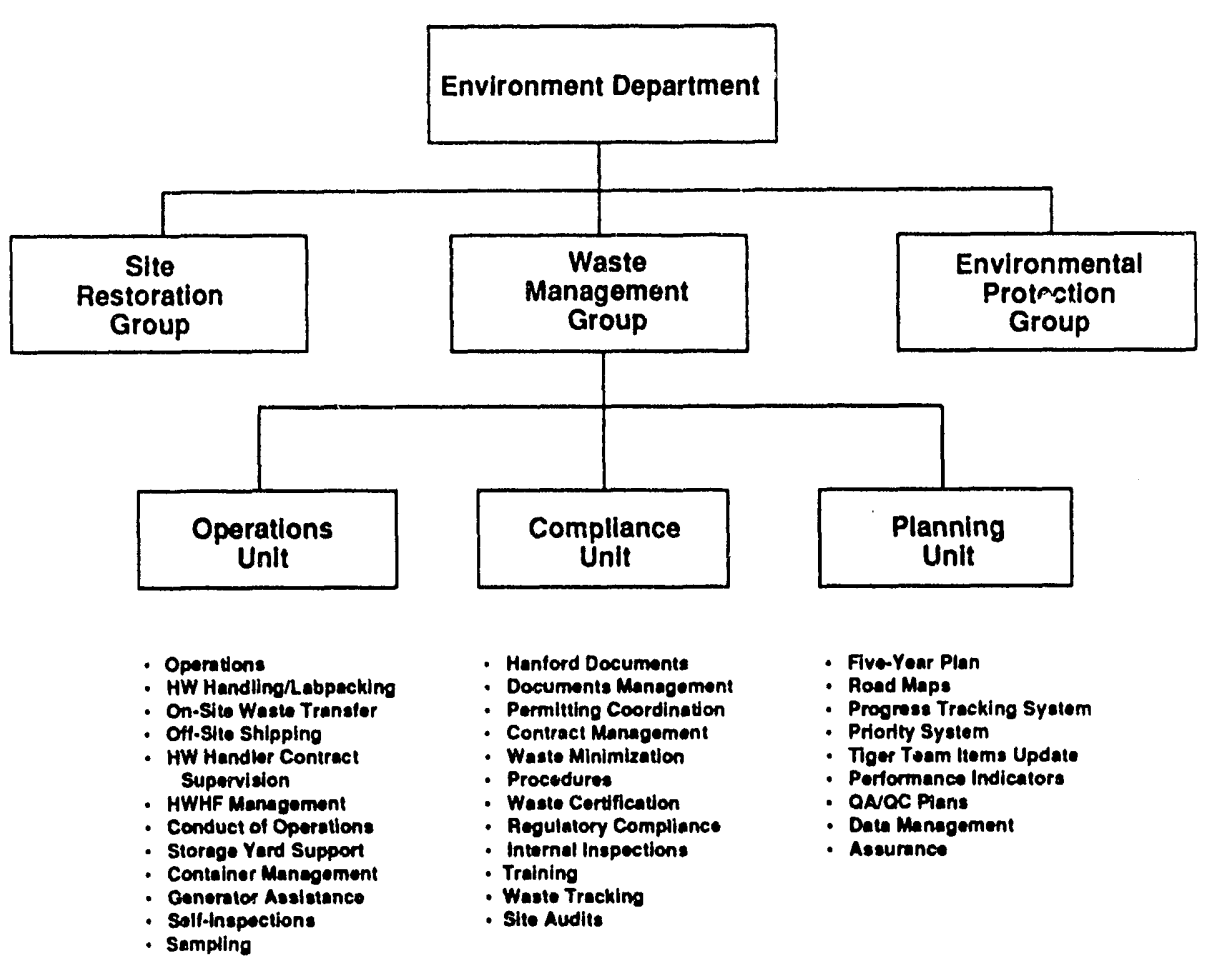

Figure 2-1. Environment Department Organization Chart 


\section{ORGANIZATIONAL FLOW CHART}

\begin{tabular}{|l|cc|}
\hline $\begin{array}{l}\text { DOE Field } \\
\text { Organizations }\end{array}$ & DOE/SF & DOE/Richland \\
DOE & LBL & $\begin{array}{c}\text { Westinghouse } \\
\text { Hanford Co. } \\
\text { Contractors }\end{array}$ \\
$\begin{array}{l}\text { Contractor } \\
\text { Sub-units }\end{array}$ & $\begin{array}{l}\text { EH\&S } \\
\text { Division } \\
\end{array}$ & \\
& HWHF \\
\hline
\end{tabular}

Figure 2-2. Organizational Flow for LLW 
- Is responsible for directing and monitoring the implementation of the HWHF QA program.

- Reviews and approves the Waste Management procedures.

- Assures that waste handling operations are conducted in accordance with the requirements of WHC-WAC [1].

- Assures that the procedures developed for LBL wastes are reviewed and updated regularly.

- Approves the development and use of calibration procedures and requirements for control of measuring and test equipment.

- Develops and keeps current the LBL Waste Management Plan [6].

\subsubsection{Operations Unit Manager, $H W H F$}

- Is responsible for the supervision of LLW handling, processing, and transportation.

- Evaluates decontamination and waste disposal work, and issues assignments to Unit members.

- Organizes and trains personnel and evaluates their performance.

- Is trained in the regulations of WAC 173-303 [2].

- Maintains up-to-date knowledge of all current Cal-EPA, DOE, and other regulations pertaining to hazardous and radioactive waste disposal for implementation within the department.

- Evaluates each LBL operation that generates LLW.

- Assures that waste is properly analyzed for a safe waste disposal system and that effective methods of minimizing and segregating wastes are instituted.

- Advises and coordinates in hazardous and radioactive waste processing. 
- Prepares for state and Federal audits and inquiries, and responds to various regulatory entities when required.

- Assures that waste disposal files are maintained.

- Interacts with regulatory agencies to maintain compliance with all regulations.

- Supervises and coordinates job assignments.

- Assures that each assigned person reads the Waste Management QAIMP and is briefed on the HWHF quality goals, areas of responsibility, and formal work controls, with emphasis on the individual's specific responsibilities.

- Assures that services, materials, equipment, and components of shipping containers are selected from supplier that meet DOT requirements, as specified in 49 CFR.

- Reviews and approves the Waste Management Program procedures.

\subsubsection{Senior Technician, $H W H F$}

- Undtr limited supervision, collects, identifies, transports, prepares, stores, and disposes of hazardous and radioactive wastes.

- Cleans up spills and decontaminates equipment/areas as required.

- Applies comprehensive knowledge of hazards associated with hazardous and radioactive materials for safe handling, possible reuse, and appropriate disposal.

- Is trained in the regulations of WAC 173-303 [2].

- Improves methods to minimize LLW.

- Maintains compliance with all applicable regulations.

- Finds vendors to provide services for disposal, recycling, and transportation of LLW and assures that such services comply with all applicable State of California, Washington State, DOE, EPA, and DOT requirements. 
- Takes prompt and appropriate action, when necessary, to prevent the effects of a detected quality problem from spreading.

- Subjects LLW generated at LBL to minimization and proper packaging for shipment to approved waste disposal sites.

- Evaluates contaminated laboratory equipment and reclaims it by chemical or physical decontamination.

- Assumes responsibility for equipment disposal based on economy and hazardous conditions.

- Works with waste generators to effect waste reduction as much as practicable.

- Investigates and implements chemical recycling programs, as practicable.

- Maintains records of waste minimization efforts.

- Generates reports as required by DOE, EPA, or other regulatory agencies.

- Maintains an adequate disassembly and decontamination facility.

- Maintains computer data on all waste streams.

- Evaluates contaminated laboratory equipment and areas, reclaiming where possible by physical or chemical decontamination.

- Maintains up-to-date knowledge of new surface materials, solutions, equipment, and techniques used for decontamination.

- Maintains all required inventories and records associated with the above duties in an accurate, current, and useful format.

- Performs other duties as directed by the Operations Manager.

\subsubsection{Technician, $H W H F$}

- Under normal supervision, performs complex duties in the field of radioisotope safety and hazardous and radioactive waste disposal and decontamination to 
achieve compliance with the LBL safety standards and with applicable legal requirements.

- Is trained in the regulations of WAC 173-303 [2].

- Monitors laboratory facilities, equipment, and personnel, decontaminating exposed areas.

- Transports, stores, and disposes of LLW.

- Keeps inspection records for all of the above.

- Evaluates contaminated laboratory equipment and reclaims it by chemical or physical decontamination.

- Assumes responsibility for equipment disposal based on hazardous conditions.

- Performs other duties as directed by the Operations Manager.

\subsubsection{Waste Certification Specialist, HWHF}

- Signs the certification statement on the Low-Level Waste Storage/Disposal Request.

- Certifies compliance with waste acceptance criteria in general, and with WHCWAC [1] and the SDAR specifically for each waste package.

- Certifies that LLW storage, packaging, waste form criteria, and waste package criteria meet the applicable requirements of WHC-WAC.

- Certifies that DOT shipping requirements for surface radiation dose rates are met.

- Certifies that labeling and marking requirements of 49 CFR 171, 172, and 173, and WHC-WAC are met.

- Certifies that the appropriate documentation and records are prepared.

- Is trained in the regulations of WAC 173-303 [2]. 


\subsection{Principal Interfaces}

\subsubsection{Internal}

HWHF personnel interface with all generators of LLW at LBL. For radioactive materials, HWHF personnel interface with users both before the research begins and after the material has been used and is intended for disposal. Interactions also occur in the case of an emergency and when calls for information regarding the handling of LLW are received from a user.

\subsubsection{External}

External interfaces occur with the Westinghouse Hanford Company's Solid Waste Engineering, material haulers, disposal facility personnel, and DOE, OSHA, State of California, University of California, and City of Berkeley personnel.

HWHF management also monitors the activities of "participating external groups," e.g., non-LBL organizations that provide services or materials for HWHF operations. The role of these groups is defined in various vendor purchase agreements. 


\section{Section 3: Certification Methodology}

\subsection{Certification Process Description}

\subsubsection{Requirements}

This plan for certification of LLW is designed to assure that all LLW from the LBL HWHF meets the waste acceptance criteria for the Hanford Site Central Waste Complex and Burial Grounds. These criteria are established in WHC-WAC [1]. The certification methodology addresses the following areas:

- Waste Reduction: LBL imposes technical and administrative controls for the minimization of LLW.

- Waste Segregation: LBL has developed technical and administrative procedures to identify and segregate LLW from hazardous waste.

- Waste Characterization: Any waste material that is known to be, or suspected of being, contaminated with hazardous components and radionuclides is fully characterized by the waste generators.

- Waste Package and Shipment: All LLW packages meet the surface dose, surface contamination, nuclear criticality, thermal power requirements, void space, and gas generation criteria imposed by WHC-WAC [1].

These criteria and LBL compliance are discussed in detail in the following sections.

Figure 3-1 shows the master flow chart for radioactive waste at LBL, with governing LBL documents listed.

\subsubsection{Certification Process Description}

Detailed flowcharts are provided for the following discrete activities within the certification process: 
Action

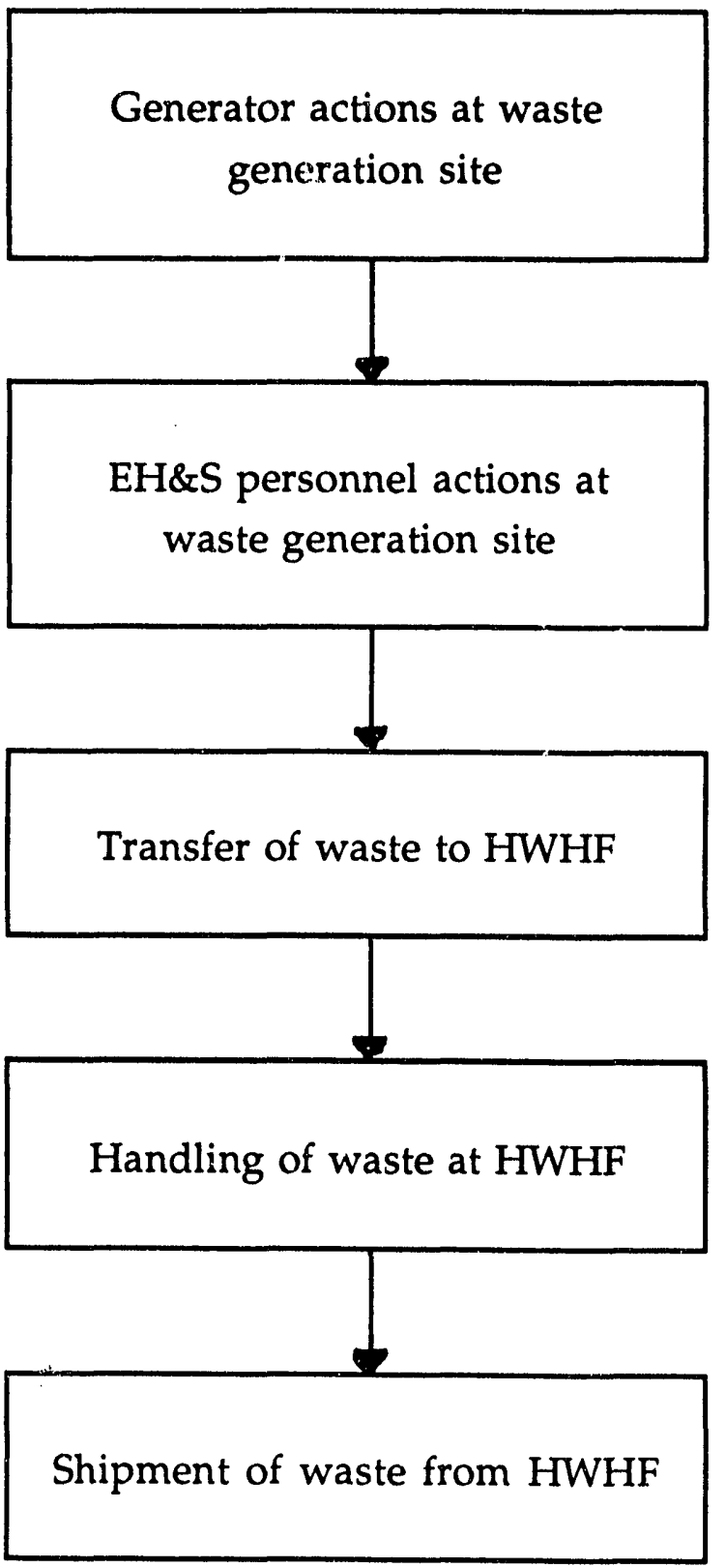

Governing LBL Documents

Generator Guides (PUB-3092)

Procedure 820

Generator Guides (PUB-3092)

Procedures $820,827,829,868$

Procedures 827, 829

Procedures $820,827,840-845,847,868.1$

Procedures 830, 831, 831.1

Figure 3-1. Master flow chart for low-level radioactive waste at LBL, with governing LBL documents listed. 
- Characterization of waste from RMMAs (Figure 3-2)

- Onsite transfer of waste to the HWHF (Figure 3-3)

- Application process for SDARs (Figure 3-4)

- Documentation and release of radioactive waste to Hanford-prior to arrival of truck that will ship the waste (Figure 3-5)

- Documentation and release of radioactive waste to Hanford-after arrival of truck that will ship the waste (Figure 3-6)

Waste Minimization. LBL has established a series of documents delineating the policy and procedural requirements for generation and control of LLW. These documents include

- Guidelines for Generators of Hazardous Chemical Waste at LBL and Guidelines for Generators of Radioactive and Mixed Waste at LBL [11] (hereinafter called Guidelines for Generators)

- Waste Management procedures (Appendix A)

- General Policy Statement for the Hazardous Waste Management Program (EH\&S Procedure 800)

- Waste Management Plan, Hazardous Waste Handling Facility, LBL [6]

- Waste Minimization and Pollution Prevention Awareness Plan [12].

These documents form the basis of technical and administrative controls imposed on the waste generators in their effort to reduce the volume and amount of LLW material requiring disposal.

LLW is assayed by the researchers, and a material balance is required. The radionuclide components are identified, and their quantities are determined and recorded at each stage of the generation process. This is done using process knowledge of the researchers or by analysis by an independent laboratory according to the requirements of 


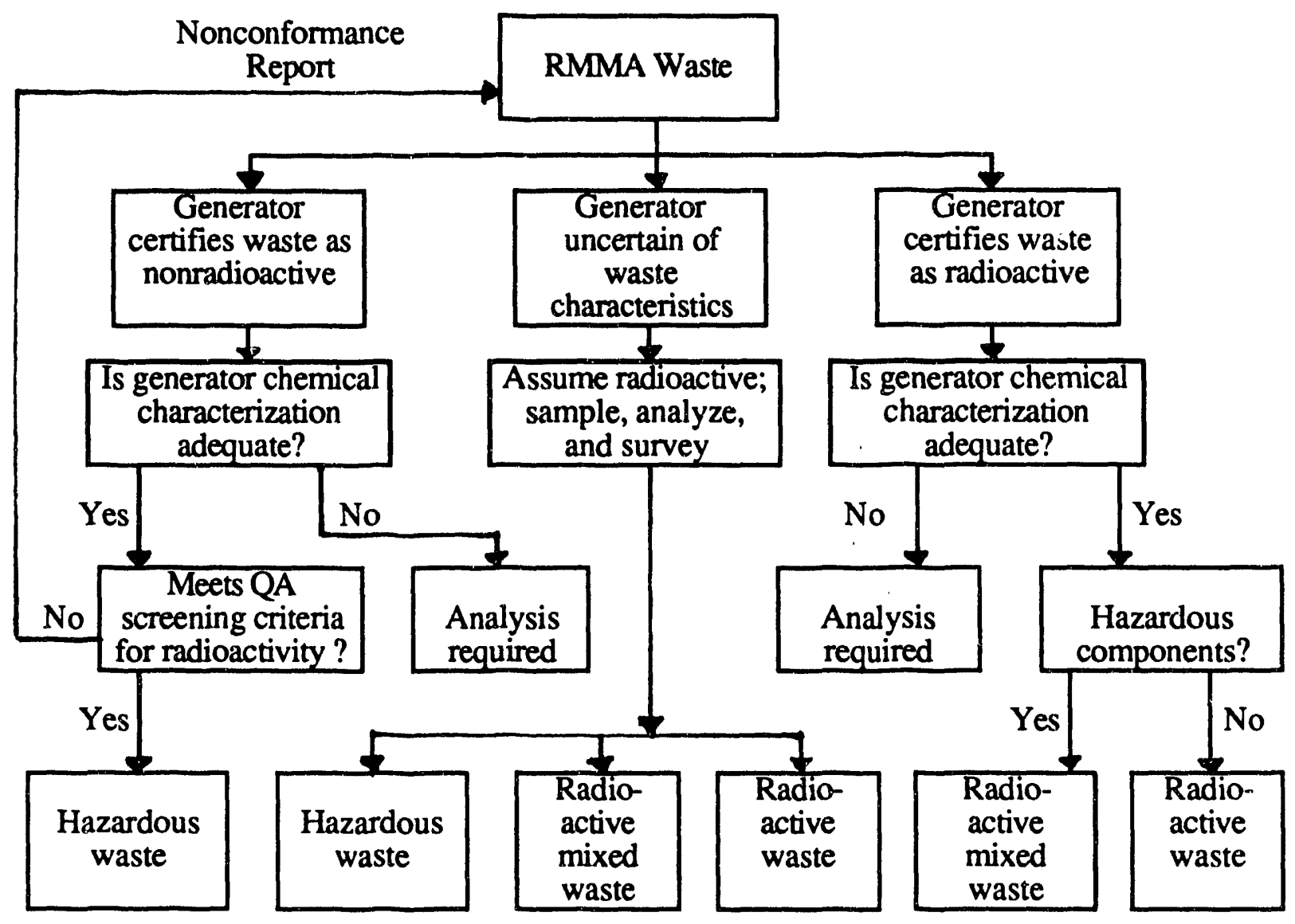

Figure 3-2. Characterization of waste from RMMAs 


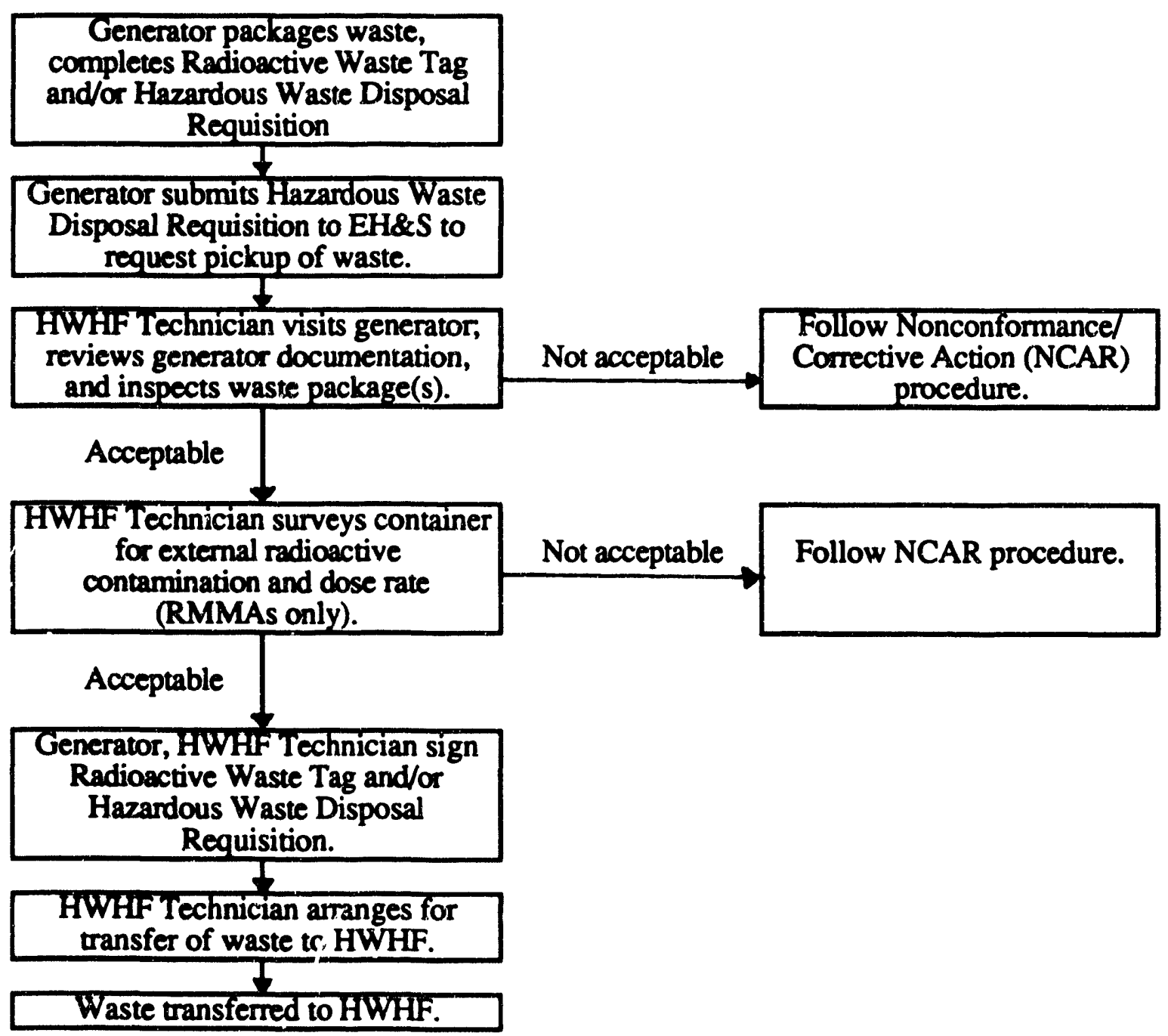

Figure 3-3. Onsite transfer of waste to the HWHF 


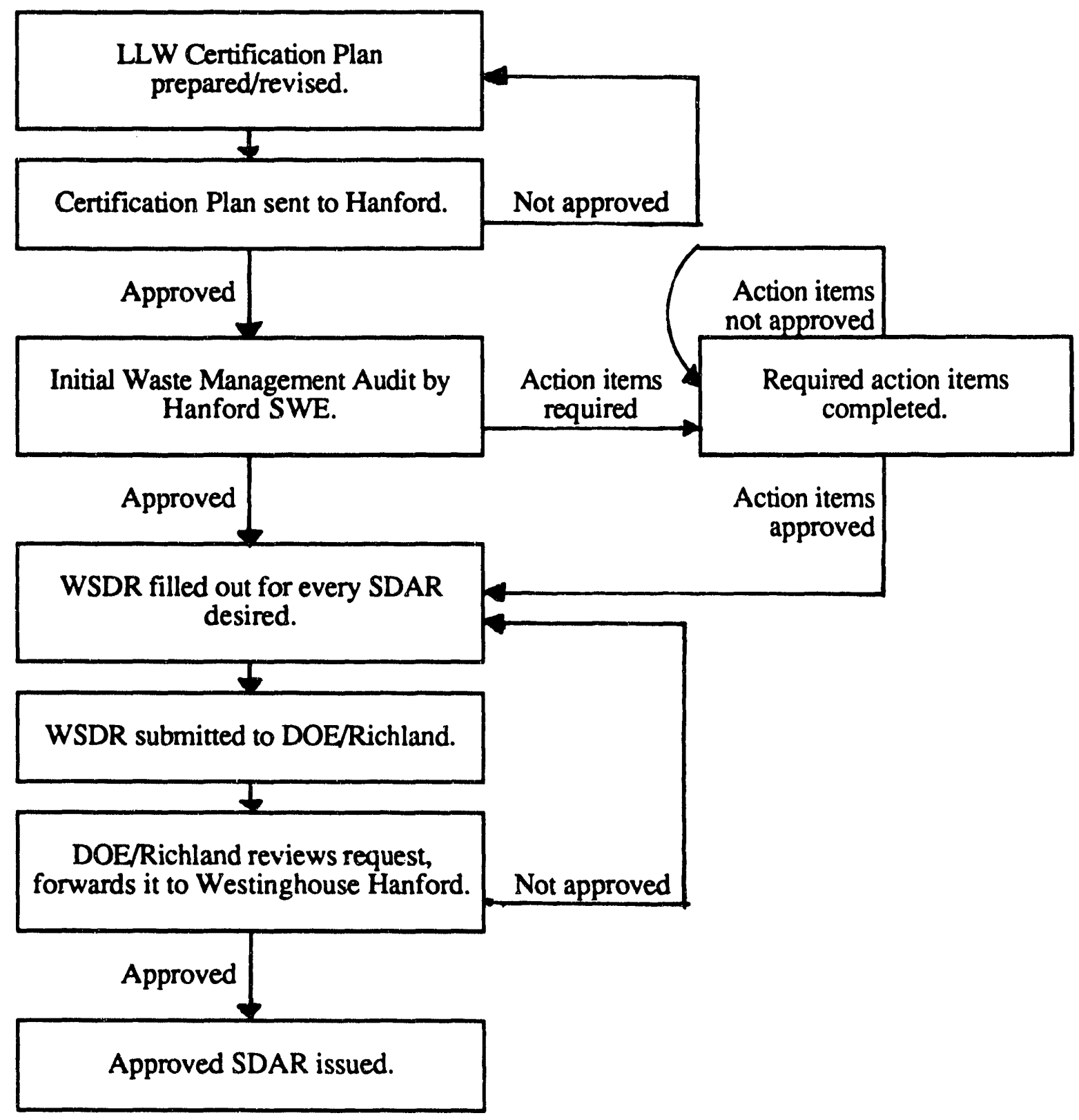

Figure 3-4. Application process for SDARs 
EH\&S Administration (*LBL Purchasing)

Submits to Purchasing a
UC Purchase Requisition
form for waste shipment
and acceptance at Hanford.

*Arranges for waste shipment with an approved hazardous waste material trucking firm.

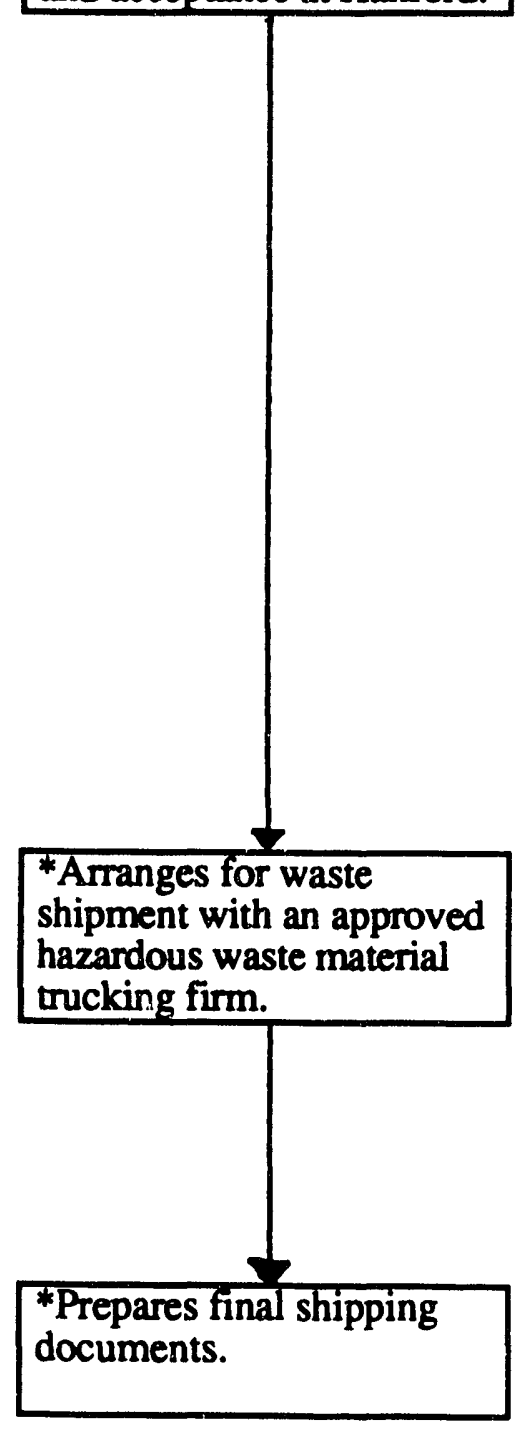

\section{Compliance Manager (†Operations Manager)}

Starts shipping arrangements by submitting General Procurement and Work Order Request to EH\&S Administration.
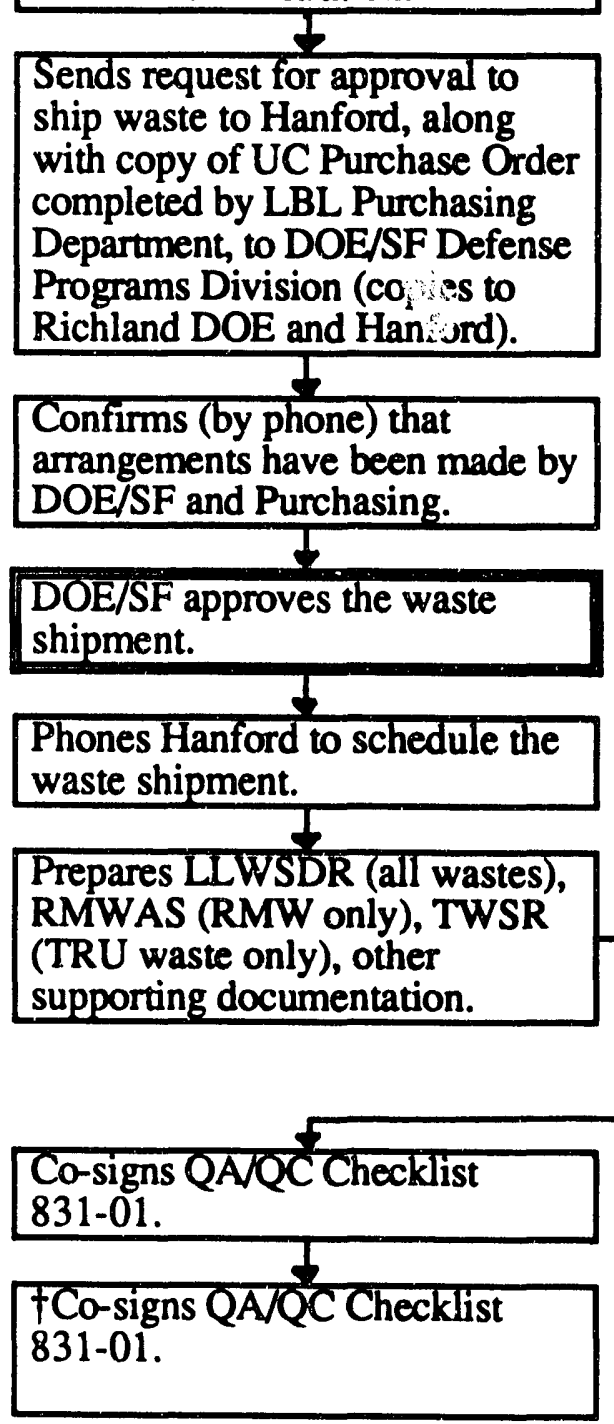

Sends request for approval to ship waste to Hanford, along with copy of UC Purchase Order completed by LBL Purchasing Department, to DOE/SF Defense Richland DOE and Han ond)

Confirms (by phone) that arrangements have been made by DOE/SF and Purchasing.

DOE/SF approves the waste shipment.

Phones Hanford to schedule the waste shipment.
Operations Unit Yard Technician

Prepares LLWSDR (all wastes),
RMWAS (RMW only), TWSR
(TRU waste only), other
supporting documentation.
conformance?

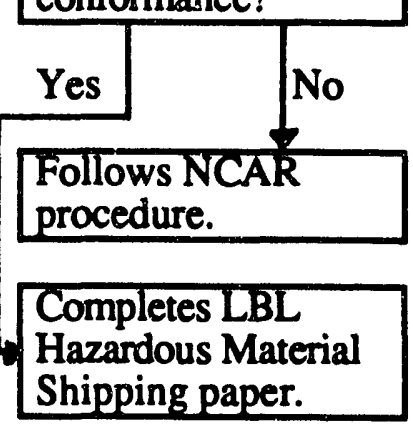

Figure 3-5. Documentation and release of radioactive waste to Hanford-prior to arrival of truck that will ship the waste 


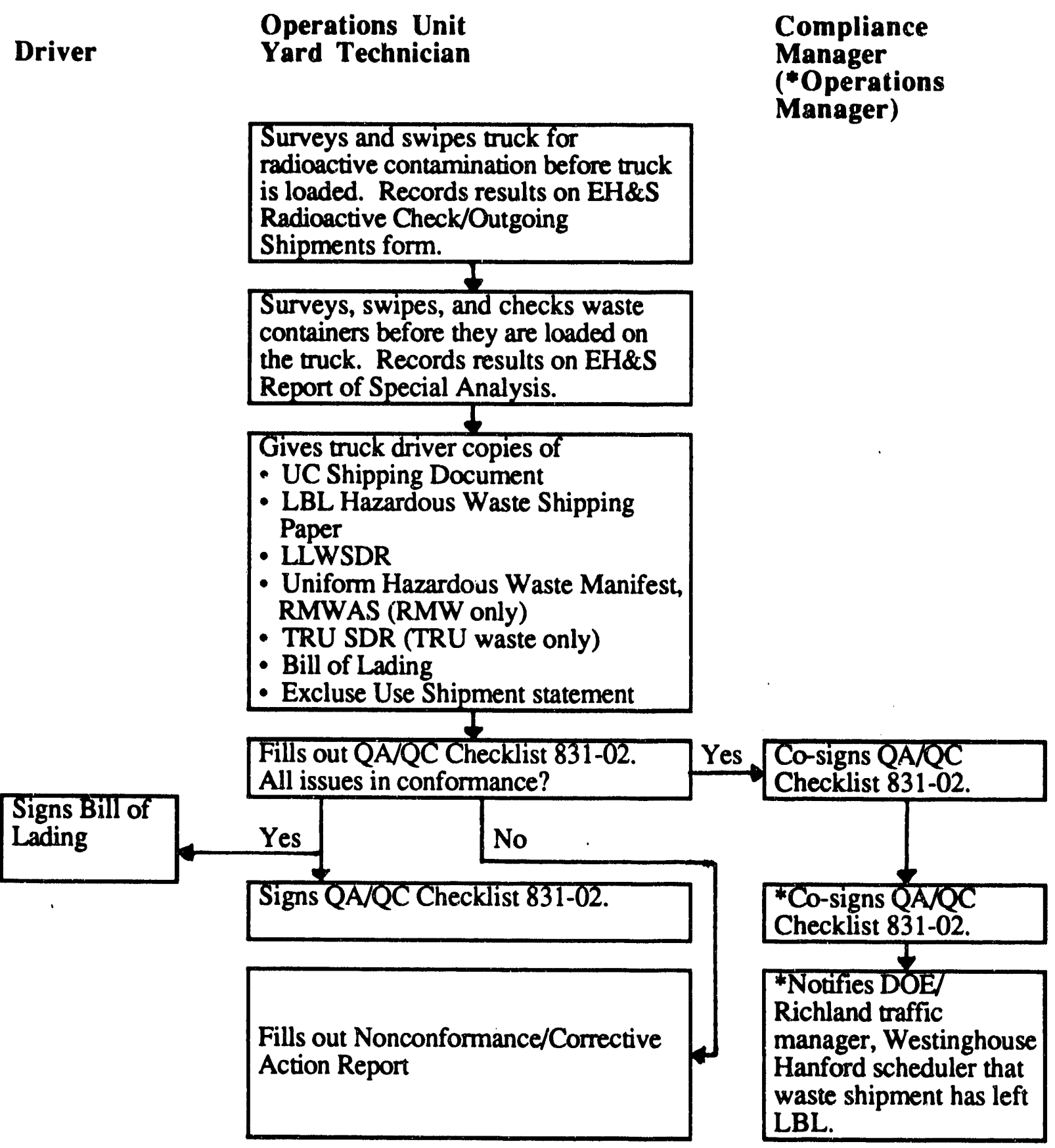

Operations Unit radioactive contamination before truck is loaded. Records results on EH\&S Radioactive Check/Outgoing Shipments form.

Surveys, swipes, and checks waste containers before they are loaded on the truck. Records results on EH\&S Report of Special Analysis.

Gives truck driver copies of

- UC Shipping Document

LBL Hazardous Waste Shipping Paper

- LLWSDR

Uniform Hazardous Waste Manifest, only)

- TRU SDR (TRU waste only)

- Bill of Lading

- Excluse Use Shipment statement

Fills out $Q A / Q C$ Checklist 831-02. All issues in conformance?

Signs Bill of Lading
Compliance

(ner

* Operations

Manager)

\section{Checklist 831-02}


the Guidelines for Generators [11]. The generation and treatment of LLW at LBL is accomplished in compliance with DOE Order 5820.2A [4] and WHC-WAC [1].

To reduce the quantities of LLW produced, individual generators are instructed to:

- Minimize the gross volume of radioactive wastes by such practices as ordering only the amount of radioactive materials and chemicals used and designing experiments to use the minimum amount of radioactive materials and chemicals needed.

- Try to modify procedures to substitute nonhazardous substances for hazardous substances.

- Recycle or reuse chemicals.

- Store radioactive wastes separately from hazardous wastes (oxidizers, explosives, flammables, poisons, toxics, and corrosives).

- Separate radioactive and mixed wastes with half-lives of 45 days or shorter from other radioactive wastes.

- Separate radioactive wastes into low-level waste, mixed hazardous and lowlevel wastes, transuranic wastes, and mixed hazardous and transuranic wastes. Keep each kind of waste in a separate container.

- Do not add radioactive waste to hazardous wastes.

Radioactive Isotope Characterization. Radionuclide accountability establishes the types and possibly the quantities of isotopes in the waste. The characterization of the waste identifies the radionuclides to satisfy the requirements of WHC-WAC [1], Section 4.3, "Waste Characterization." This includes the radionuclide distribution, concentration, and activity in the waste matrix. The characterization procedures assure that a realistic representation of the distribution of radionuclides within the waste is provided (given physical limitations). LBL radionuclide characterization procedures are detailed in the Guidelines for Generators [11] and specific Waste Management procedures. 
LBL personnel using radionuclides are responsible for characterizing the waste generated in their work areas. Their responsibilities are outlined in the Guidelines for Generators [11]. Radioactive materials are analyzed before and after each chemical or physical operation. These assays are used to determine the material balance for each amount of radionuclide placed in the waste. Radioactive contaminated items are surveyed with appropriate portable instruments, and the estimated amounts of activity are determined. Both the physical and chemical composition of the waste and the radionuclides are identified by the user, aided by the HWHF Field Technician. This information is recorded on the Radioactive Waste Tag attached to each package before the waste package is removed from the user's area. The Field Technician examines each waste package for accuracy before removing it from the user's area.

Physical/Chemical Characterization. Waste certification includes the determination of the physical and chemical characteristics of the waste, including any void filling material or absorbent. Physical/chemical characterization is accomplished similarly to the method used to characterize the radionuclide content of the waste, i.e., by use of process knowledge, indirect correlation, laboratory analysis, and inventory accountability.

As a minimum, the characterization of waste includes the following information:

- physical and chemical characteristics of the waste and any void-filling material or absorbent

- volume of the waste (total of waste and any solidification or absorbent media)

- weight of the waste (total of waste and any solidification or absorbent media)

- packaging details

- packaging date, package weight, and total volume

- transportation category [e.g., low specific activity (LSA), Limited Quantity, Type A, per 49 CFR 173].

Waste Handling and Packaging Activities. The certification process includes handling and packaging waste in accordance with procedures that assure that the waste is packaged and records generated in a manner that fulfills the requirements of WHC-WAC 
[1] and the appropriate Storage/Disposal Approval Record (SDAR). This also includes the means to identify and document what is placed in waste containers and the means to prevent unauthorized or incorrect material from being placed in waste containers.

Containers meet the following handling criteria:

- All containers used for LLW with maximum gross weights of $<16,000 \mathrm{lb}$ are compatible with forklift handling.

- Containers used for LLW storage are designed to withstand the weight of two layers of $55 \mathrm{mgal}$ drums stacked on top with $1,000 \mathrm{lb}$ in each drum

- Crane-unloaded containers used for LLW are equipped with lifting devices designed to safely lift the fully loaded container. All lifting attachments are designed with a 5:1 safety factor based upon the ultimate strength of the materials or a 3:1 safety factor based on the yield strength of the materials, whichever is more conservative. The waste package itself is designed with a 2:1 safety factor based on yield strength of the materials. Lead must not be used in fabricating the rigging.

- Rigging details are provided to Westinghouse Hanford by the generator at least 2 weeks before each shipment if special rigging or lifting is required. An additional copy is sent with the shipment. Details include a sketch showing overall dimensions, lift points, weights at each lift point, and centers of gravity of the object. If available, sketches of strong backs of lift rigs used for loading are furnished. All rigging complies with the Hanford Site hoisting and rigging requirements.

Surface dose rates for all packaged waste meet the requirements of 49 CFR 173.441 [8]. The maximum surface-radiation dose rate for any one package does not exceed the following:

- Contact-handled radioactive waste packages sent to disposal facilities

- Contact-handled 55-gal drums or smaller packages: $200 \mathrm{mrem} / \mathrm{h}$ at any point on the surface 
- Contact-handled waste packages larger than 55-gal drums: Normal surface radioactivity must not exceed $200 \mathrm{mrem} / \mathrm{h}$. However, a marked point with surface radioactivity up to $1,000 \mathrm{mrem} / \mathrm{h}$ on the bottom and one side may be permitted with preapproval of Westinghouse Hanford Solid Waste Engineering. Such points must be marked with large orange, yellow, or red painted dots.

- Remote-handled radioactive waste packages prepared for crane or drag-off unloading must include sacrificial rigging provided by the shipper. The rigging must be packaged in such a manner that it may be attached to handling equipment without exposing field personnel to excessive radioactivity. Offloading personnel must not work in fields in excess of $100 \mathrm{mrem} / \mathrm{h}$. Waste generators must notify the scheduler and obtain approval from Solid Waste Operations if radiation fields in excess of $100 \mathrm{mrem} / \mathrm{h}$ are measured. A special radiation work permit and an ALARA management worksheet are required onsite when dose rates exceed $1 \mathrm{rem} / \mathrm{h}$ at $3 \mathrm{ft}$.

- Waste packages sent to the Central Waste Complex: $100 \mathrm{mrem} / \mathrm{h}$ at any point. (Packages up to $200 \mathrm{mrem} / \mathrm{h}$ may be received at the Central Waste Complex. A justification for exceeding the $100 \mathrm{mrem} / \mathrm{h}$ limit must accompany the request for storage of this waste. Approval by Solid Waste Operations is required before receipt of waste packages that exceed $100 \mathrm{mrem} / \mathrm{h}$ ).

- Waste packages inside returnable overpacks: Surface dose rates do not exceed limitations discussed in this section. In addition, the inner package is suitably rigged such that personnel are not exposed to a radioactive field in excess of $100 \mathrm{mrem} / \mathrm{h}$ while removing overpacks or attaching prepared riggings to crane hooks or similar equipment.

Other packaging criteria meet the following:

- Removable surface contamination does not exceed:

$-220 \mathrm{dpm} / 100 \mathrm{~cm}^{2}$ for alpha contamination

$-2200 \mathrm{dpm} / 100 \mathrm{~cm}^{2}$ for beta/gamma contamination 
- There is no fixation of surface contamination on returnable overpacks. Removable surface contamination on the interior surfaces of returnable overpacks is less than 100 times the above limit.

- Nuclear criticality limits are met if waste packages contain $15 \mathrm{~g}$ of ${ }^{235} \mathrm{U}$ or less. Limits for packages containing more than $15 \mathrm{~g}$ are determined by WHC on a case-by-case basis.

- Thermal power acceptance criteria included in the SDAR are met.

- Catalysts or vents required by the SDAR are properly used.

- The interior void space within containers does not exceed $10 \%$ of the container volume unless exempted by the SDAR. Interior void spaces include any opening within the waste matrix that exceeds 2 in. in diameter. Spaces smaller than 2 in. need not be included in the void calculation. Spaces larger than 2 in. must be filled with void-filling material.

All the LLW packages are labeled or marked with the following information:

- WRM number

- PIN (Each waste package must bear a unique PIN. The numbering system used for the PIN is given in WHC-WAC, Appendix I [1].)

- Gross weight in pounds or kilograms

- DOT radioactive hazard class labels as required

- "This end up," or directional arrows marked on the sides and near the top to indicate proper package orientation for packages containing inner containers of liquid. (Inner containers must be marked as to their contents.)

- The following warning on the sides of drums or on at least two sides of rectangular packages for packages containing asbestos: 


\section{CAUTION \\ Contains Asbestos \\ Avoid Opening or \\ Breaking Container \\ Breathing Asbestos is Hazardous \\ to Your Health}

The warning above is specified in 40 CFR 61.152 [7]. Alternately, the following Occupational Safety and Health Administration (OSHA) standard label can be used, as specified in WAC 296-62-07721 [2]:

\section{DANGER \\ Contains Asbestos Fibers \\ Avoid Creating Dust \\ Cancer and Lung Disease Hazard \\ Avoid Breathing Airborne Asbestos Fibers}

- The following information is marked on the side of each drum containing free organic liquids in inner containers:

\section{- LIQUID ORGANIC WASTE}

- The flash point or flash point range (for flammable or combustible materials with flash points below $200^{\circ} \mathrm{F}$ ) of the material in degrees fahrenheit (e.g., flash point $160-180^{\circ} \mathrm{F}$ )

- Additional labeling and marking requirements are included in specific SDARs.

- All labeling and marking conforms to the requirements in 49 CFR 171, 172, and $173[8]$.

- Labels and marking are permanently applied with paint or other materials. Labels and markings on stored LLW have a predicted 20-year life expectancy and are compatible with the container and protective coating. Labels and markings on disposed LLW have a predicted 1-year life expectancy in the Hanford Site environment (uncovered).

- All labels and markings are in clear, legible English and in a color contrasting with the background. For stored LLW, stencils (for paint-applied markings) or adhesive labels are used for all markings.

- All labels and markings are nonfading and nonsmearing. 
- Drums banded to pallets are positioned to permit visual inspection of the labels and markings.

Character size criteria for the PIN, WRM number, gross weight, and "Bottom Tier Only" markings include the following:

- Characters used in labeling and marking drums or cylindrical containers $\geq 30$ gal and $\leq 55 \mathrm{gal}$ are at least $1 \mathrm{in}$. high.

- Characters used in labeling and marking drums or cylindrical packages $\geq 30 \mathrm{gal}$ are legible at $5 \mathrm{ft}$.

- Characters used in labeling and marking other LLW packages smaller than 12 $\mathrm{ft}^{3}$ are at least 1 in. high.

- Characters used in labeling or inarking LLW packages $\geq 12 \mathrm{ft}^{3}$, or cylindrical packages larger than 55-gal drums, are at least 2 in. high.

All other characters are legible at $5 \mathrm{ft}$.

All labeling and marking is placed on LLW packages in the following locations unless otherwise noted on the SDAR.

- Drag-off boxes: All required markings and labels are placed once each on two vertical sides.

- Other rectangular waste packages: All required markings and labels are placed once each on at least two vertical sides of the package. The PIN, gross weight, and WRM number are also placed on the top of the package.

- Cylindrical waste packages: All required markings and labels are placed once on the side of the package, aligned with the locking bolt on the drum lid. The PIN, gross weight, and WRM number are also placed on the top of the package. 
- Cylindrical waste packages in horizontal orientation: All required markings and labels are placed once on the side of the package. The PIN, gross weight, and WRM number are also be placed on one end of the package.

Procedures for shipping LLW are included in the EH\&S procedures listed in Appendix A. Quality control measures are outlined in Section 4 and the Waste Management QAIMP [13].

"One-trip" packagings used by the LBL HWHF are mainly 55-gallon DOT 17C or $17 \mathrm{H}$ drums used for the transport and burial of radioactive waste.

Two other shipping packages are used to dispose of large contaminated items:

(1) A 52" wide x 89" long x 55" high wood burial container, LBL Drawing No. HCD 69806E. The container design conforms to RH-CD-767, "Design Criteria Burial Containers for Nontransuranic Solid Radioactive Waste," American Plywood Association design specification, with the addition of 1.25-inch steel strapping for further integrity.

(2) A 2' deep x 4' wide x 8' long plywood box, LBL Drawing 22J1223C, for shipment of induced metals and materials. The box has been approved by Westinghouse Hanford for shipment of these wastes and is part of SDAR 87-6C-3A-0301, approved 2/10/92.

\subsubsection{Procedures and Processes Common to All Waste Streams}

Qualification and Training. All users of radioactive materials are required to attend EH\&S Courses 430 (Radiation Protection), 343 (Hazardous Waste Generators), and 347 (Radioactive and Mixed Waste). All attendees of Courses 343 and 347 receive copies of the Guidelines for Generators [11].

HWHF personnel receive extensive training on the handling of radioactive wastes, as well as handling of hazardous wastes. A complete list of training received by HWHF personnel is maintained by the HWHF Administrative Assistant. 
Management Assessment. The Waste Management QAIMP [13] provides the oversight for HWHF certification activities to assure that these activities result in the management of waste in accordance with WHC-WAC [1]. This oversight is accomplished through the use of audits, quality surveillance, and reviews of related activities. Corrective actions and control of nonconforming items are addressed in the QAIMP and Section 4 of this document.

HWHF management reviews and assesses these procedures and processes to assure that the generators characterize the waste adequately and provide adequate environment, health, and safety protection. If deficiencies are found, HWHF management assesses the need for changes and provides the mechanisms needed to make the required changes in the procedures and processes.

Activities Common to Most Waste Streams. A number of activities are common to all waste generators regardless of waste stream. These activities are handled in a uniform manner. Model procedures are prepared by EH\&S. These model procedures are then incorporated in the facility's procedural manual and tailored to suit the situation for each waste stream. A list of these common activities follows:

- Generators and HWHF personnel handle radioactive wastes separately from all other wastes.

- Generators are scrupulous about good housekeeping in hoods, glove boxes, and laboratories.

- Generators keep the buildup of radioactive wastes to a minimum. As soon as waste containers (ice cream cartons, waste sacks in garbage cans) are filled, they are removed to the HWHF.

- Generators characterize and minimize all radioactive waste to the fullest extent possible.

- Generators provide the primary waste containers (ice cream containers, plastic bags, etc.); HWHF personnel provide approved waste collection containers (galvanized waste cans, five-gallon carboys, etc.).

- All radioactive waste is collected from the generators and transported to the HWHF by HWHF or contract personnel. At the HWHF, personnel review 
each waste package for proper contents and accurate identification on the Radioactive Waste tag.

- HWHF personnel prepare, package, store, and arrange for offsite disposal of the waste.

- No liquid radioactive waste is poured down the sanitary drains. EH\&S is notified immediately if liquid radioactive waste is inadvertently poured down a drain.

- No explosives, flammables, or highly toxic chemicals are discarded with radioactive dry wastes.

- All sharp objects (hypodermic needles, scalpels, etc.) are placed in protective containers.

- Where required, ventilation and filtration systems are provided for all radioactive waste disposal operations to maintain radionuclides releases well below DOE guidelines.

\subsection{LLW, Solid Compacted}

\subsubsection{Description}

This waste stream is made up of dry solid laboratory waste contaminated with radioactive substances.

\subsubsection{Characterization Methodology}

The generator is responsible for characterizing the radioactive, physical, and chemical content of the waste and accurately completing the Radioactive Waste tag for each package. This waste stream is characterized in accordance with the requirements of the SDAR and the guidance provided in the Guidelines for Generators [11]. 


\subsubsection{Segregation Methodology}

Researchers are trained iu ceparate LLW from hazardous wastes. Segregation methodology is provided in the Guidelines for Generators [11].

\subsubsection{Waste Handling. Packaging, and Shipping Operations}

- The wastes are packaged at the generator areas in cement sacks inside a 24 " $x$ 38 " polyethylene bag, all placed inside a 15 -gallon waste can.

- At the HWHF, the bags are compacted (4-to-1 compaction) in a 55-gallon DOT $17 \mathrm{C}$ or $17 \mathrm{H}$ drum, using a compactor.

- The wastes are stored in the drums until they are shipped for disposal. Specific handling, packaging, and shipping procedures are provided under the Waste Management Program procedures listed in Appendix A.

\subsection{LLW, Solid Noncompacted (Drums)}

\subsubsection{Description}

This waste includes laboratory hardware over 4" $\times$ 4" $\times$ 4"-large solid items such as iron, plastic, ring stands, etc.

\subsubsection{Characterization Methodology}

The ge nerator is responsible for characterizing the radioactive, physical, and chemical content of the waste and accurately completing the Radioactive Waste Tag for each package of radioactive waste. This waste stream is characterizet, segregated, and packaged in accordance with the appropriate SDAR and the guidance provided in the Guidelines for Generators [11]. 


\subsubsection{Segregation Methodology}

Researchers separate noncompactible waste, transuranic waste, mixed waste, and short-lived radioisotopes from solid waste. Segregation methodology is provided in the Guidelines for Generators [11].

\subsubsection{Waste Handling, Packaging, and Shipping Operations}

The waste is contained at the generator's area in cement sacks inside a 24 " $\times 38$ " polyethylene bag, all placed inside a 15-gallon waste can. The wastes are stored in the drums until they are shipped. Specific handling, packaging, and shipping procedures are provided under the Waste Management Program procedures listed in Appendix A.

\subsection{LLW, Noncompacted (Wooden Boxes)}

\subsubsection{Description}

This waste stream includes laboratory hardware over 4" x 4" x 4." This waste stream differs from the low-level radioactive waste stream (solid noncompacted, drums) only in that the waste is too large to fit into the 55-gallon barrels.

\subsubsection{Characterization Methodology}

The generator is responsible for characterizing the radioactive, physical, and chemical content of the waste and accurately filling out the Radioactive Waste tag for each package of radioactive waste. This waste stream is characterized, segregated, and packaged in accordance with the appropriate SDAR and the guidance provided in the Guidelines for Generators [11].

\subsubsection{Segregation Methodology}

Researchers separate the noncompactable waste, transuranic waste, mixed waste, and short-lived radioisotopes from solid waste. Whenever possible, the researcher cleans 
items to remove hazardous substances. Segregation methodology is provided in the Guidelines for Generators [11].

\subsubsection{Waste Handling, Packaging, and Shipping Operations}

These wastes are self-contained or wrapped in plastic if containment is required. At the HWHF, the wastes are consolidated in DOT-approved wooden boxes. The boxes meet all specifications per LBL Drawing No. HCD 69806E. This type of wooden box is approved by the Hanford Burial Site. Specific handling, packaging, and shipping procedures are provided under the Waste Management Program procedures listed in Appendix A.

\subsection{LLW, Induced Metals and Materials}

\subsubsection{Description}

Most of this waste is made radioctive by bombardment with neutrons or charged particles produced by the LBL accelerators.

\subsubsection{Characterization Methodology}

The generator is responsible for characterizing the radioactive, physical, and chemical content of the waste and accurately filling out the Radioactive Waste tag for each package of radioactive waste. This waste stream is characterized, segregated, and packaged in accordance with the appropriate SDAR and the guidance provided in the Guidelines for Generators [11].

\subsubsection{Segregation Methodology}

LBL researchers and EH\&S employees monitor all items and separate nonradioactive metals from this waste. Segregation methodology is provided in the Guidelines for Generators [11]. 


\subsubsection{Waste Handling, Packaging, and Shipping Operations}

The induced metals are self-contained, and large pieces are tied to pallets by the generator. Small pieces are contained in wooden boxes. At the HWHF, personnel reduce the volume of this waste stream by cutting and fitting together the items during packaging. Materials suitable for placement on pallets are put on pallets. Small items not suitable for palletizing are packaged in wooden boxes. The wastes are stored at Building $75 \mathrm{~A}$ until they are shipped. Waste items too large to be placed in the approved wooden box are placed on fire-retardant pallets and stored at the generator's site until they are shipped. Specific handling, packaging, and shipping procedures are provided under the Waste Management Program procedures listed in Appendix A.

\subsection{LLW, Animal Carcasses}

\subsubsection{Description}

This waste stream is made up of laboratory animal carcasses or tissues contaminated with radioisotopes. The waste is frozen, contained in plastic bags, and stored in freezers located at the animal research laboratories, where they are kept until shipment to the disposal site.

\subsubsection{Characterization Methodology}

The generator is responsible for characterizing the radioactive, physical, and chemical content of the waste and accurately filling out the Radioactive Waste tag for each package of radioactive waste. This waste stream is characterized in accordance with the appropriate SDAR and the guidance provided in the Guidelines for Generators [11].

All radioactive animal carcasses are packaged in slaked lime in accordance with the procedures developed by the Washington Department of Social and Health Services. This ensures that calcium hydroxide is $<10 \%$ by weight of the waste. If this is the case, and calcium hydroxide is the only dangerous material present, then the carcass is not subject to regulation as a dangerous waste per the WAC 173-303-84 [2]. Animal carcasses will not be received for disposal unless they have been packaged accordingly. Animal carcasses preserved with formaldehyde are not suitable for disposal at the Hanford Site. 


\subsubsection{Segregation Methodology}

Researchers separate all carcasses into those containing short half-life isotopes $(<40$ days) and long half-life isotopes ( $>40$ days). Hazardous materials are not injected into animals. Nonradioactive carcasses are disposed of as regular garbage. Segregation methodology is provided in Guidelines for Generators [11].

\subsubsection{Waste Handling, Packaging, and Shipping Operations}

At the HWHF, personnel package the animal carcasses in 30-gallon DOT 17C drums, which are then placed in 55-gallon drums. The procedure consists of first lining 30-gallon drums with a 4-mil (minimum) polyethylene liner. The animal carcasses are placed in the drum, with a mixture of one part lime to ten parts diatomaceous earth by weight. The amount of absorbant is sufficient to absorb twice the volume of liquid potentially present. The liner is pigtailed and sealed with 2 -inch-wide plastic-reinforced cloth tape. The inner drum is sealed with a drum lid, locking ring, locking ring nut, and lock nut. A minimum of three inches of absorbant is placed in the bottom of the outer drum, a DOT $17 \mathrm{C}$ or $17 \mathrm{H} 55$-gallon drum. The inner (30-gallon) drum is placed in the 55gallon outer drum. The void space between the two drums is filled with absorbant. The drum closure is secured by a gasketed drum lid, locking ring, and lock ring nut. The locking ring nut is torqued, and a lock nut is applied. Specific handling, packaging, and shipping procedures are provided under the Waste Management Program procedures listed in Appendix A.

\subsection{LLW, Absorbed Tritium}

\subsubsection{Description}

The main generator of this waste is the National Tritium Labeling Facility (NTLF) at LBL. Compounds are tagged with ${ }^{3} \mathrm{H}$. Up to $200 \mathrm{Ci}$ are used at one time. Unused ${ }^{3} \mathrm{H}$ is transferred and held in a storage tank. 


\subsubsection{Characterization Methodology}

The generator is responsible for characterizing the radioactive, physical, and chemical content of the waste and accurately filling out the Radioactive Waste tag for each package of radioactive waste. This waste stream is characterized, segregated, and packaged in accordance with the appropriate SDAR and the guidance provided in the Guidelines for Generators [11].

Tritiated waste is waste containing $>20 \mathrm{mCi}$ of tritium/ $\mathrm{m}^{3}$ of waste $(4.2 \mathrm{mCi} / 55-\mathrm{gal}$ drum). The disposal acceptance criteria for tritiated waste are:

- Liquid tritiated waste is absorbed on an inert absorbent material within an inner leak-resistant container. The quartity of absorbent material is sufficient to absorb twice the quantity of liquid tritiated waste potentially present.

- Inner containers with $<100 \mathrm{Ci}$ tritium $/ \mathrm{m}^{3}$ (21 Ci/55-gal drum) of either absorbed liquids or solids are either sealed in one layer of $4 \mathrm{mil}$ (nominal) or thicker polyethylene, or coated with 10-mil-thick (minimum) virgin asphalt, and disposed in a steel or concrete container.

- Inner containers with $\geq 100 \mathrm{Ci}$ tritium $/ \mathrm{m}^{3}$ (21 Ci/55-gal drum) are coated completely with 1 -in-thick (minimum) virgin asphalt and disposed in a steel or concrete container.

- Sealing systems not dependent on asphalt diffusion barriers have been used to contain tritium. All welded structures, bellows-sealed valving, and flanged joints with metallic gaskets and knife-edged sealing surfaces have been used for tritium-containing materials. Such systems are acceptable for disposing tritium provided suitable technical data are furnished by the shipper to demonstrate that the tritium-containing capability of containers based on these systems is equivalent to or better than that of the asphalt barrier system.

\subsubsection{Segregation Methodology}

The plastic bottles containing the waste are kept separate and not mixed with any other wastes by the generators. Segregation methodology is provided in the Guidelines for Generators [11]. 


\subsubsection{Waste Handling, Packaging, and Shipping Operations}

NTLF personnel collect the ${ }^{3} \mathrm{H}$ and convert it to HTO (tritiated water) by passing it over a hot $\mathrm{CuO}$ bed and collecting the HTO in a condenser. The radioactive water is drained into polyethylene bottles that contain silica gel, absorbing the water. The bottles are packaged in one-gallon cans. Those cans with more than $1 \mathrm{Ci}$ of HTO are filled with asphalt, with at least a 1 -inch thickness on all sides of the can. The cans are sealed with a canning machine and stored in Building 75A until shipment. Specific handling, packaging, and shipping procedures are provided under the Waste Management Program procedures listed in Appendix A.

\subsection{LLW, Liquid Solidified}

\subsubsection{Description}

This waste consists of research laboratory solutions with radioisotopes and nonhazardous substances.

\subsubsection{Characterization Methodology}

The generator is responsible for characterizing the radioactive content of the waste and accurately filling out the Radioactive Waste Tag for each package of radioactive waste. Before the wastes are solidified, they are analyzed for total activity. This waste stream is characterized, segregated, and packaged in accordance with the applicable SDAR. Before and after the wastes are solidified, they are analyzed for organics and heavy metals. Guidance on characterization is provided in the Guidelines for Generators [11].

Disposal Criteria. Packages of LLW containing wastes in liquid form are disposed of in the Hanford Site 200 Area facilities. All liquids disposed of as LLW are solidified, absorbed, or otherwise bound in the waste matrix by inert materials. The resultant waste matrix is not capable of spontaneous combustion, decomposition, explosion, liquid desorption, or affecting the integrity of the containment barriers in any way.

If the resultant waste matrix is capable of gas generation, the container is vented and contains catalyst packs to deplete oxygen and prevent explosive concentrations of hydrogen 
or other explosive gases (e.g., methane, volatile organic compounds) and oxygen. The use of vents or catalyst packs is specified in the applicable SDAR. If used, the catalyst packs will be palladium on alumina or platinum on silica, depending on the potential amount of moisture present in the waste package. The amount of catalyst required will be based on the amount of potential hydrogen generation and will be specified in the applicable SDAR.

If liquids are bound by absorption, the absorbent material is placed in direct contact with the liquid. The quantity of absorbent material is sufficient to absorb twice the volume of liquid potentially present or as specified in the SDAR. Combustible absorbent (Conwed pads or equivalent) is used with organic liquids. Noncombustible absorbent is not accepted with organic liquids since this material interferes with future processing of that liquid. A list of acceptable absorbents and void fillers is contained in WHC-WAC, Appendix K [1].

Storage Criteria. Some LLW in liquid form (such as some scintillation liquids and nonhazardous liquid organics with properties incompatible with land disposal) is accepted for storage at the Hanford Site 200 Areas facilities to eventually be destroyed when a waste processing facility becomes available. Liquids accepted for storage may be absorbed as described above, packaged as described below, or packaged as described in the applicable SDAR. Liquids to be stored are not solidified in concrete or grout unless approved by WHC.

The liquid is sealed in leak-resistant containers of not more than 5-gal rated capacity for plastic or metal and 1-gal rated capacity for glass. The total quantity of liquids per each 55-gal drum does not exceed $15 \mathrm{gal}$. The inner container is packaged with a combustible absorbent such as Conwed pads or approved equivalent for absorption of oils. Sufficient absorbent is included in the package to absorb at least twice the maximum amount of liquids potentially present.

If the resultant waste matrix is capable of gas generation or pressure buildup, the container is vented and contains catalyst packs to deplete oxygen and prevent explosive concentrations of hydrogen or other explosive gases (e.g., methane, volatile organic compounds) and oxygen. The use of vents or catalyst packs is specified in the applicable SDAR. If used, the catalyst packs will be palladium on alumina or platinum on silica, in the amount specified in the applicable SDAR.

If liquids are bound by absorption, the absorbent material is placed in direct contact with the liquid. The quantity of absorbent material is sufficient to absorb twice the volume 
of liquid potentially present or as specified in the applicable SDAR. The absorbent is selected based on the final treatment or disposal technology employed. The applicable SDAR specifies the absorbent to be used. Liquids are not absorbed, solidified, or otherwise packaged without the concurrence of WHC.

\subsubsection{Segregation Methodology}

Researchers separate all hazardous solutions (RMW) from nonhazardous solutions. They identify all reagents in the liquid waste. Segregation methodology is provided in the Guidelines for Generators [11].

\subsubsection{Waste Handling, Packaging, and Shipping Operations}

The waste is contained in the generator's area in glass or plastic bottles. At the HWHF, the wastes are analyzed for radioactivity. If the radioactivity is unusually high, the Field Technician contacts either the waste hauler or the researcher for additional information. The liquid is checked for $\mathrm{pH}$. If the $\mathrm{pH}$ is $1-3$, the acid is neutralized. After these procedures are done (if necessary), the liquid is poured into a 55-gallon DOT $17 \mathrm{C}$ or $17 \mathrm{H}$ drum and mixed with absorbant (a mixture of portland cement and diatomaceous earth) until it is solidified. The drums are stored in Building 75A until they are shipped to the disposal site. Specific handling, packaging, and shipping procedures are provided under the Waste Management Program procedures listed in Appendix A.

\subsection{Methodology for Infrequent or Unforseen Waste Certification}

The methodology for infrequent or unforeseen waste certification will follow the methodology established for the most similar existing waste stream, with those modifications necessary for health, safety, environmental protection, and adequate characterization and packaging of the waste. Basic methodologies follow.

- Generators will be responsible for characterizing all aspects of the waste (radioactive, hazardous, nonhazardous), as established in existing procedures for the various waste streams. Generators will also be responsible for segregating and separating the waste, as established in existing procedures for the various waste streams. 
- Sampling will be done at the HWHF as necessary to characterize the waste.

- A task team will be set up to determine the best way to apply for the proper SDAR.

- All other procedures will follow existing practice as closely as possible, allowing for the differences in the new waste streams.

\subsection{Minimization}

The Waste Minimization and Pollution Prevention Awareness Plan [12] provides the policy, strategy, objectives, and goals for waste minimization at LBL. Waste minimization techniques are applied through:

- inventory management

- operational procedures

- a maintenance program

- material changes and process equipment modification

- recycling and reuse.

A training program provides LBL employees with instruction on the implementation of the waste minimization plans. Tracking and reporting systems and the Waste Management QAIMP [13] provide a means to verify the implementation of the waste minimization plan activities.

Policies currently in place at LBL to achieve waste minimization include

- holding short-lived isotopes at HWHF for decay

- keeping contaminated and noncontaminated items separate

- using good housekeeping in hoods, glove boxes, and laboratories

- reusing or decontaminating solid noncompacted waste (drums, wooden boxes) 
- instructing researchers to avoid introducing items needlessly into radiation fields

- instructing researchers to use the minimum amount of material necessary

- instructing researchers to use nonhazardous materials instead of hazardous material whenever possible

- disposing of explosive, flammable, or highly toxic chemical wastes separately from radioactive waste (no mixing)

- requiring all employees to take EH\&S courses 430 (Radiation Protection), 343 (Hazardous Waste Generators), and 347 (Radioactive and Mixed Waste), which include training in waste minimization and disposal procedures

- keeping buildup of all wastes to a minimum.

\subsection{Segregation}

Specific segregation instructions are contained in the Guidelines for Generators [11]. LLW is segregated to reduce any hazardous waste components using standardized processes and methods. LLW is segregated into separate waste containers to avoid mixing with other waste streams.

The HWHF establishes the policy and procedures for the minimization and segregation of LLW in the Waste Minimization and Pollution Prevention Awareness Plan [13] and the Waste Management Program procedures listed in Appendix A.

\subsection{Onsite Treatment and Storage}

LBL has submitted the Part B Permit Application for all LBL treatment processes to Cal-EPA for approval. Various treatment processes are included. For example, liquid radioactive material is evaporated in glove boxes, if practicable, and packaged in LBLcertified containers. The generator is required to chemically, radiologically, and physically characterize the LLW, prior to any waste pick-up and transport to the HWHF by the technician. The waste is stored at the HWHF in DOE approved 55 -gallon drums $(17 \mathrm{H}$ or 17C). 


\subsection{Waste Characterization, Sampling, and Analysis}

\subsubsection{Characterization}

All LLW is properly characterized chemically, radiologically, and physically. Prior to the approval of the transfer of any waste to the HWHF, the generator is required to estimate the radioactive and chemical concentrations or amounts of contaminating radionuclides using process knowledge or laboratory analysis as defined in Guidelines for Generators [11]. Upon completion, the generator certifies that the waste has been accurately and completely characterized. The HWHF Field Technician then reviews the information for accuracy in accordance with applicable regulations and monitors, tags, and packages the wastes for onsite transport to the HWHF.

The generator, with assistance from the HWHF Field Technician, reviews each waste stream against the lists of wastes identified in California Regulations, including:

- The "Hazardous Waste from Non-Specific Sources" list (F-List), 40 CFR 261.31

- The "Hazardous Waste from Specific Sources" list (K-List), 40 CFR 261.32

- The "Discarded Commercial Chemical Products, Off-Specification Species, Container Residues, and Spill Residues Thereof" list (P-List and U-List), 40 CFR 261.33

Each waste stream must also be characterized, either by generator certification or by hazard categorization, to identify its hazardous waste characteristics:

- ignitability, as defined in 40 CFR 261.22

- corrosivity, as defined in 40 CFR 261.22

- reactivity, as defined in 40 CFR 261.23

- toxicity, as defined in 40 CFR 261.24 
- biologic (infectious) nature as defined in the California Health and Safety Code, Section 25117.5 [15].

All LLW is characterized to demonstrate thet it is LLW as defined in accordance with DOE Order 5820.2A [4]. Radionuclide constituents are individually identified by isotope, and their concentrations are determined. The method used to determine isotope concentration is documented on the HWHF Radioactive Waste tag.

In addition, all LLW is physically characterized to demonstrate that it meets the specifications required by WHC-WAC [1]. Any deficiency is clearly indicated so that the waste can be properly treated prior to final packaging for shipment to the disposal site.

Characterization data includes all radionuclides that contribute $>1 \%$ (by Curies) of the total activity of the waste matrix, and any of the following radionuclides even if they contribute $<1 \%$ of the total activity (if in greater than class A quantities; see 10 CFR 61.55 [16]): ${ }^{3 \mathrm{H}},{ }^{14} \mathrm{C},{ }^{60} \mathrm{Co},{ }^{59} \mathrm{Ni},{ }^{63} \mathrm{Ni},{ }^{79} \mathrm{Se},{ }^{90} \mathrm{Sr},{ }^{94} \mathrm{Nb},{ }^{99} \mathrm{Tc},{ }^{129} \mathrm{I},{ }^{241} \mathrm{Pu},{ }^{242} \mathrm{Cm},{ }^{137} \mathrm{Cs}$, and alpha-emitting nuclides with half-lives $>5 \mathrm{yr}$. Reporting of the radionuclides includes any parent-daughter radionuclide pairs that meet the above criteria (e.g., ${ }^{137} \mathrm{Ba}$ must be reported with ${ }^{137} \mathrm{Cs},{ }^{90} \mathrm{Y}$ must be reported with ${ }^{90} \mathrm{Sr}$ ).

Naturally occuring radioisotopes are reported on the LLWSDR form if they meet the above requirements and are the reason for the waste being declared radioactive, or if they have been enriched in any way. If these isotopes are incidental to fission or activation products that cause the waste to be declared radioactive, then the naturally occuring radioisotopes need not be entered on the LLWSDR form.

\subsubsection{Waste Sampling and Analysis}

LLW sampling and analysis is performed in accordance with recognized industry methods and standards. The sampling procedures used by the HWHF to characterize radioactive waste are presented in the Waste Analysis Plan [14]. Sampling and analysis provide for an accurate representation of the waste in accordance with statistically valid or EPA-approved methods. It is the policy of the HWHF that ten percent of the waste packages accepted for disposal are verified by an independent laboratory for the accuracy of information provided on the Radioactive Waste tags. Generators should refer to the 
Guidelines for Generators [11] for specific parameters of analysis, sampling techniques, and types of containers required for adequate waste sampling and analysis.

For circumstances where sampling and analysis are not feasible or necessary for characterization of radioactive constituents, techniques that rely primarily on knowledge of the process can be used. This process knowledge is reviewed and approved by the Waste Certification Specialist. Documentation of this process knowledge is a requirement.

\subsection{Waste Form Criteria}

LLW containing significant concentrations of ${ }^{14} \mathrm{C},{ }^{79} \mathrm{Se},{ }^{99} \mathrm{Tc}$, or ${ }^{129} \mathrm{I}$ has been determined to pose a long-term health hazard. These wastes are evaluated for storage or disposal acceptability on a case-by-case basis. Significant concentrations of these radionuclides are concentrations that exceed the Class I levels indicated in WHC-WAC, Section 4.3 [1].

LLW forms capable of generating toxic gases, vapors, fumes, or liquids are not accepted (as indicated in DOE Order 5820.2A, Chapter III, section 3.i.[5][d]) [4]. Wastes with this capability are reacted or ot ierwise stabilized in an approved manner. Specific waste forms that could be stored or disposed at the Hanford Site 200 Areas facilities also meet the waste form criteria described in the following.

\subsubsection{Asbestos}

All LLW containing asbestos must be packaged in accordance with the requirements of 40 CFR 61.152 [7]. If 40 CFR 61.152 section (b) (1) (iii) is used, then the following applies: The material must be wetted, placed in a 4-mil or heavier plastic bag, and sealed wet using 2 -in-wide, fabric-reinforced tape or approved equivalent. The water used in this case is considered to be part of the packaging and not a free liquid. The material must then be packaged in a leak-resistant container that meets applicable shipping requirements for the radioactive content of the package involved. Sharp edges and corners within the package must be padded or otherwise protected to prevent damage to the plastic inner wrap during handling and shipping.

The outer package must be marked with the proper asbestos warning label as outlined in WHC-WAC Section 4.7.4 [1] and 40 CFR 61.152(b) (1) (iv) [7]. 


\subsubsection{Ion Exchange Resins}

All ion exchange resins disposed as LLW must be thoroughly drained and stable, and must not react with normal surroundings to create excessive heat or corrosive-reactive products. The container must be vented, or a catalyst pack may be required if the ion exchange resin is capable of gas generation.

All resins received at the Site 200 Areas facilities for disposal must be evaluated for hazardous waste content. Sufficient data must be provided by the generator so that a regulatory designation can be performed in accordance with WAC 173-303 [2]. Data provided must include a processing history, which should describe any materials absorbed on the resin in processing; chemical compositions of column washes; operating temperatures; and dates of column loading, unloading, and operation. Nitrated organic resins are not normally suitable for disposal. If the resins contain hazardous material, the waste must comply with WHC-WAC Chapter 5.0 or 6.0 [1].

\subsubsection{Alkali Metals}

Acceptance criteria for LLW contaminated with alkali metals are as follows:

- Waste items accepted for burial must not have unreacted alkali metal contamination that would require regulation of the material as RMW.

- Components having surface-adherent alkali metal contamination resulting from operational history must be processed to react and remove residual material from internal and external surfaces via either alcohol or moist gas processing before packaging for disposal. Very small amounts of adherent alkali metals can be removed by water immersion or wiping with moist rags if the operation can be done safely.

- Containers may require vents or other approved devices as specified in the applicable SDAR if alkali-metal-contaminated waste is capable of gas generation.

- Ancillary materials resulting from working with, or cleanup of, radioactive alkali metals must be individually visuaily inspected for the presence of 
unreacted alkali metals or residuals before packaging for disposal. Any evident alkali metal contamination must be removed. The remaining material must be verified free from any reactive residuals by standard alkali metal cleaning techniques: moist rag or steam or water bath, as appropriate.

- For materials unable to meet the above criteria, Westinghouse Hanford Solid Waste Engineering must determine, based on quantity of alkali metals present, whether the waste should be classified as RMW and handled according to the requirements in WHC-WAC, Chapter 5.0 or 6.0 [1].

\subsubsection{Explosives and Compressed Gases}

The following criteria apply to explosives and compressed gas cylinders in LLW packages:

- The waste must not be capable of detonation, explosive decomposition, reaction at normal pressures and temperatures, or explosive reaction with water.

- The waste package must not contain, or be capable of generating, quantities of toxic gases, vapors, or fumes harmful to persons transporting, handling, or disposing of the waste.

- Waste in a gaseous form must be packaged at a pressure that does not exceed 1.5 atmospheres at $20^{\circ} \mathrm{C}$. Gas cylinders must be permanently vented. Aerosol cans are allowed if the container has been punctured or otherwise vented or if the propellent has been exhausted.

\subsubsection{Pyrophoric Materials}

Pyrophoric materials in LLW packages must be rendered safe through mixture with chemically stable materials such as glass or concrete, or through processing to remove the hazardous properties.

\subsubsection{Classified Waste}

Some forms of low-level radioactive waste are classified for security reasons. Waste generators must include the fact that the waste they intend to ship to the Hanford Site is 
classified as part of their initial request for approval to store or dispose of the waste. Westinghouse Hanford will also need sufficient information about the nature of the classification, the type of packaging, and the way in which the waste will be shipped (i.e., SST or other method) to provide adequate security. Special packaging, shipping, and handling requirements will be managed on a case-by-case basis and will be provided in the SDAR.

\subsection{Waste Package Criteria}

\subsubsection{Packaging}

All LLW packages accepted for disposal by WHiC meet the criteria listed in the following sections.

\subsubsection{Surface Dose Rates}

Waste packages have a maximum surface dose rate at contact not greater than 100 $\mathrm{mrem} / \mathrm{h}$ (beta, gamma, and neutron) at any point. Packages up to $200 \mathrm{mrem} / \mathrm{h}$ may be received at WHC; however, justification for exceeding $100 \mathrm{mrem} / \mathrm{h}$ is needed, and approval by Hanford Solid Waste Operations is required before receipt of the waste package.

HWHF personnel measure surface dose rates according to the applicable procedure. Maximum contact surface dose rates are entered on the LLWSDR. Recorded surface dose rates are dose rates at the highest measured points on the surface of the drum or the box.

\subsubsection{Surface Contamination}

LLW waste packages have no removable surface contamination exceeding 220 $\mathrm{dpm} / 100 \mathrm{~cm}^{2}$ for alpha contamination and $2,200 \mathrm{dpm} / 100 \mathrm{~cm}^{2}$ for beta-gamma contamination.

HWHF personnel monitor waste drums and waste boxes for removable surface contamination using swipe techniques according to EH\&S Procedure 868. 


\subsubsection{Nuclear Criticality}

Nuclear criticality safety is provided for LLW by limiting the fissile content of the waste packages. Limits for waste packages that contain more than $15 \mathrm{~g}$ of ${ }^{235} \mathrm{U}$ are determined by WHC Solid Waste Engineering on a case-by-case basis. These limits are indicated in the SDAR. Waste packages containing $15 \mathrm{~g}$ of ${ }^{235} \mathrm{U}$ or less do not require a separate criticality safety analysis.

\subsubsection{Thermal Power}

The acceptance criteria for waste package exceeding 0.1 watt/ $/ \mathrm{f}^{3}$ are included in the applicable SDAR. Each waste package meets the requirements of 49 CFR 173.442 for heat generation and temperature [8].

An Operations Unit Technician performs calculations for thermal power output in accordance with procedures specified in Appendix D of WHC-WAC [1].

\subsubsection{Gas Generation}

When the use of catalysts or vents is required for LLW packages, it is specified in the applicable SDAR. Liners other than plastic bags are provided, with positive gas communication to the outer container.

\subsubsection{Interior Void Spaces}

Bulky or heavy waste items are blocked inside the container to prevent shifting during handling and transport. Void spaces within the container do not exceed $10 \%$ of the container volume.

\subsection{Containers}

Containers must be in good condition, with no visible cracks, holes, dents, bulges, corrosion, or other damage that could compromise integrity. Any containers that are bulged, corroded, or otherwise damaged are not used. The waste container is repaired, or 
the waste is repackaged or overpacked in a container meeting the criteria of WHC-WAC [1].

Containers are not used for shipment or storage of wastes that could react with or degrade the container by physical, chemical, or radiological mechanisms, unless internal container protection has been provided and documented in the LLWSDR.

Waste containers specifically marked for radioactive application are not used for nonradioactive purposes. Solid waste generated in RMMAs, if determined to be contaminated, is accumulated, if practical, in containers meeting the criteria in this manual. Otherwise, the accumulation container is overpacked in a container that does meet these requirements or the waste is transferred to one that does.

Cardboard or fiberboard boxes are not used for the containment of LLW. LLW to be compacted is packaged in plastic bags and transported in a reusable container. Specific criteria for compactible LLW are contained in the applicable SDAR.

Fifty-five-gallon drums are banded in groups of four and palletized to facilitate offloading by forklift.

\subsubsection{Types and Specifications}

All LLW shipments are packaged in DOT-specification containers appropriate to the classification of the waste stream and as specified in the applicable SDAR. All LLW accepted for storage at Hanford Site 200 Area facilities is packaged in DOT-specification $17 \mathrm{H}$ or $17 \mathrm{C}$ steel 55-gallon drums. Other containers may be approved in the applicable SDAR. Exterior surfaces of 55-gallon drums must be either painted or galvanized in accordance with specification HS-V-P-0010-A [1]. Protective coatings for waste packages larger than 55-gallon drums are specified in the SDARs for individual waste streams.

\subsubsection{Procurement}

The container type is approved by the HWHF Waste Certification Specialist prior to actual procurement. The approval is based on actual testing performed at LBL or by certification in writing from the vendor that the containers meet the design requirements. The vendor is required to submit all documentation related to the method used to 
demonstrate compliance. This procurement process is presented in detail in EH\&S Procedure 822, Container Procurement, Receipt, and Control.

\subsubsection{Receipt and Inspection}

Prior to use of any containers, they are inspected inside and out by a trained HWHF Technician. Inspection is conducted on receipt to ensure that the containers have not been damaged in a way that will affect their integrity.

The drum is inspected for

- dents

- deformation of sealing surfaces

- continuity of welds

- surface coating, and lack of imperfections

- rust and nicks.

The results of this inspection, as well as the name of the person conducting the inspection, are submitted to the Waste Certification Specialist, who is knowledgeable in the criteria for determining the extent of any damage to a container and corresponding reduction of its integrity. This receipt and inspection process is presented in EH\&S Procedure 822, Container Procurement, Receipt, and Control. Documentation tests conducted on drums to qualify them as DOT Specification Type A container are filed with the HWHF.

\subsubsection{Control}

Containers used for onsite transfer of LLW to the HWHF from the generator facilities are approved for onsite use and in good condition, with no signs of damage that could affect the containment capability.

Containers used for packaging and transportation of LLW from LBL to the disposal site are controlled to ensure that the integrity to the container has not been affected during 
packaging or handling. EH\&S Procedure 822 is used to ensure that the intemal, as well as the external, surfaces have not been unacceptably damaged. These containers are also managed to avoid adverse influence from weather or other factors on the containment capability of the waste package while it awaits packaging, is packaged, or awaits transfer after closure.

\subsubsection{Containment}

All LLW packages include at least two containment barriers, or as specified in the applicable SDAR, to prevent the release of contamination. External containment barriers are jeopardized by wind, blowing sand, precipitation, sunlight, extreme temperatures, or stresses due to the weight or configuration of the container or its contents plus the loads associated with handling and transportation.

Examples of two containment barriers include a plastic bag or a plastic liner inside a steel drum, or a steel drum inside another steel drum. Construction material of the container is compatible with the contained waste.

The following containers are exempted (as specified in the applicable SDAR) from the double-containment requirement by WHC but provide at least one containment barrier:

- Containers that have been demonstrated by engineering analysis or testing to meet the appropriate DOT Drop Test and Penetration Test requirements in 49 CFR 173, Subpart I [8]

- Self-contained and other waste packages containing DOT LSA or limited quantities of radioactive materials that only require strong, tight containers

- Heavy-walled, high-pressure equipment that meets the following requirements:

- A life expectancy in excess of $300 \mathrm{yr}$, when buried at the Hanford Site

- External wall thickness of $1 \mathrm{in}$. or more carbon or stainless steel with openings welded closed using 1 -in.-thick or heavier covers, or an approved equivalent

- No TRU or hazardous materials contained internally or on external surfaces 


\subsubsection{Fire Retardancy}

All containers used for disposal of LLW, with the exception of plastic wrap contained therein, are constructed of metal or are fire-retardant. Containers for storage of LLW are constructed of metal. As a minimum, all exterior surfaces of wooden containers are treated for fire retardation with a fire-retardant coating having a maximum flame-spread index of 25 when tested to American Society for Testing Materials (ASTM) Standard E-8484a [17].

\subsection{Shipping}

\subsubsection{Labeling and Marking}

All LLW packages shipped to the Hanford Site 200 Area for storage or disposal meet the labeling and marking criteria specified in 49 CFR 171, 172 [8] and those of WHC-WAC [1].

\subsubsection{Packaging}

Packaging for the different LLW streams is described in the EH\&S procedures listed in Appendix A.

\subsubsection{Handling}

All waste packages from $\mathrm{LBL}$ are provided with permanently attached skids, cleats, offsets, rings, handles, or other auxiliary lifting devices to allow handling by means of a forklift, crane, or similar handling equipment. Additional handling requirements specified in WHC-WAC [1] are also followed.

\subsubsection{Manifests}

Wastes shipped offsite are manifested. The driver is given copies of

(1) University of California shipping document 
(2) LBL Hazardous Materials Shipping Paper

(3) Hanford Operation Low-Level Waste Storage/Disposal Record

(4) Bill of Lading

(5) Exclusive Use Shipment Statement.

The driver signs the Bill of Lading. The details for a waste manifest are delineated in EH\&S Procedure 831, Radioactive Waste Documentation/Release Procedures for Shipments to Hanford Burial Site.

\subsubsection{Transportation}

EH\&S Procedure 827, Onsite Transportation of Radioactive and Radioactive Mixed Waste from the Site of Generation to the $H W H F$, describes onsite transport procedures for low-level waste. EH\&S Procedure 828, Offsite Transfer of Radioactive Waste to the $H W H F$, describes procedures for transporting low-level waste over public roads to the HWHF. EH\&S Procedure 831 describes procedures for preparing low-level waste for transport to the Hanford site.

Onsite Transfers. Type A quantities of radioactive waste are transported in cans that are placed in $17 \mathrm{H}$ drums or lockable boxes permanently bolted to the trucks. Liquid waste has absorbent material in the can surrounding the container of the liquid.

Offsite Transfers. Offsite transfers of LLW are done in DOT-specification containers in accordance with WHC-WAC [1] requirements. Type A wastes have shipping papers and DOT-specification marking and labeling. Limited quantities will have a limited quantity statement attached.

\subsection{Certification, Data Collection, and Record Keeping}

\subsubsection{Certification Procedure}

Certified waste is waste that has been confirmed to comply with disposal/storage site waste acceptance criteria under an approved certification program. 
Certification is the process of assuring that each waste package complies with all applicable criteria for offsite shipment, storage, and disposal. For LBL, this includes meeting WHC-WAC [1].

It is the responsibility of the LBL Waste Certification Specialist to sign the certification statement on the LLWSDR.

Compliance with waste acceptance criteria includes proper performance of the following:

- Identifying the waste through characterization or through sampling and analysis

- Packaging

- Labeling and marking

- Documenting the waste

For each waste package, the Waste Certification Specialist certifies adherence to

- All governing regulations

- All applicable storage/disposal-site waste acceptance criteria

- All requirements specified in the SDAR for a particular type of waste

The Waste Certification Specialist certifies that the requirements of WHC-WAC [1] are met.

In addition to shipping papers, the following documentation is prepared accurately and completely and certified by the Waste Certification Specialist for each LLW package accepted for storage or disposal at the Hanford Site 200 Areas facilities:

- DOE/NRC 741 form, if the waste contains accountable nuclear material (The comments of more than one waste package may be included on this form.)

- LLWSDR

- Rigging details for special handling, as required 


\section{Section 4: Quality Assurance}

\subsection{QA Organization, Duties, and Responsibilities Summary}

The LBL Waste Management Quality Assurance Implementing Management Plan (QAIMP) [13] describes the Quality Assurance organization, duties, and responsibilities for the management of activities required to handle, store, and prepare for shipment LLW at LBL. The program has been designed to ensure that generated waste meets the following:

- WHC-WAC [1]

- NQA-1-1989, Quality Assurance Program Requirements for Nuclear Facilities

- DOE Order 5700.6C, Quality Assurance [18]

- DOE Order 5820.2A, Radioactive Waste Management [4]

- Title 40 CFR [7]

The Waste Management QAIMP is the written quality assurance program plan required by the Uaiversity of California Lawrence Berkeley Laboratory Institutional Quality Assurance Program Plan (IQAPP) for EH\&S activities related to the HWHF.

\subsection{Summary of the Facility Quality Assurance Program}

The Waste Management QAIMP establishes the framework and requirements that are met in planning, implementing, documenting, and verifying HWHF activities. The subsections that follow identify the implementing plans and procedures.

\subsubsection{Organization and Responsibilities}

The organizational structure, functional responsibilities, level of authority, lines of communication, and the interface relationship required for activities affecting the quality of the waste handling program are delineated in the CAIMP. Figures 4-1 and 2-1 show the organizational relationships of positions. 


\section{Environment, Health \& Safety Division}

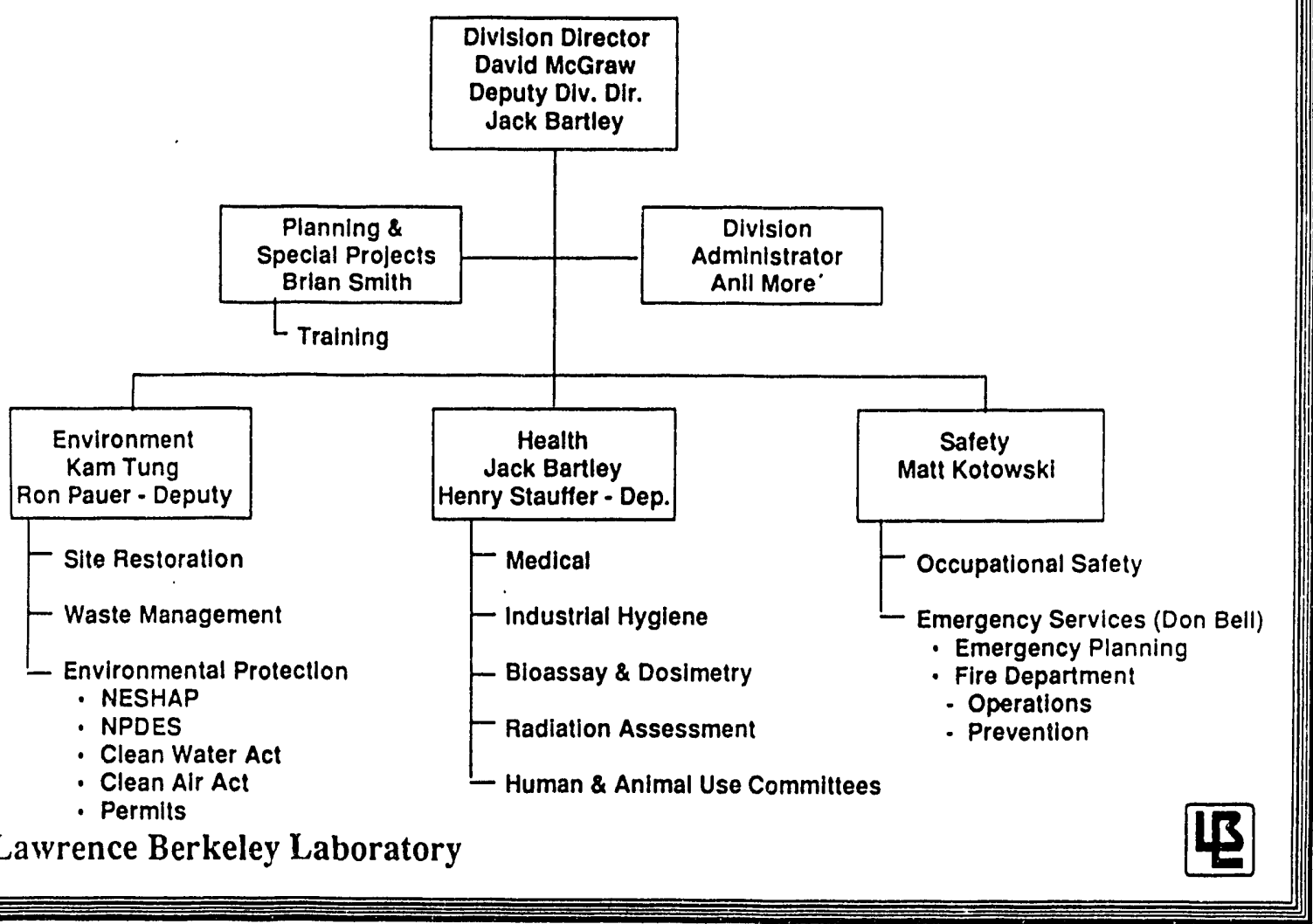

Figure 4-1. EH\&S Organization 


\section{Eunctional Responsibilities}

\section{Associate Laboratory Director. Operations:}

- Has overall responsibility for the implementation of the QAIMP in the HWHF.

- Assures that resources necessary to implement the QAIMP are provided.

- Approves the use of the QAIMP and any revisions.

\section{Division Director. Environment. Health. and Safety (EH\&S) Division:}

- Is responsible for directing and monitoring the implementation of the QAIMP.

- Reviews and concurs in the use of the QAIMP and any revisions.

\section{Department Manager. Environment Department:}

- Is responsible for directing and monitoring the HWHF QA Program.

- Issues the QAIMP and any revisions.

- Assures that audits and reviews are conducted as specified in the QAIMP.

- Assures that the necessary corrections, identified as a result of the QA audits and reviews, are accomplished in a timely manner.

\section{Operations Manager. HWHE:}

- Is responsible for plans and supervision of the HWHF.

- Evaluates disposal work and issues assignments to members of the section.

- Organizes training for members of the HWHF, as well as LBL waste generators.

- Assures that waste is properly analyzed and that effective methods of minimizing and segregating waste are instituted. 
- Assures that the waste disposal files are maintained.

\section{EH8:SOA Management:}

- Reviews QA training to ensure that competence is attained, as required by the LBL Institutional QA Plan.

\section{EH\&S OA Program personnel:}

- Assure that quality is achieved and maintained by those who have responsibility for the work.

- Verify achievement of quality.

- May delegate work but not responsibility.

- Have the authority, access, and freedom to identify quality problems; initiate, recommend, or provide solutions to quality problems; verify implementation of solutions; and assure proper disposition of nonconformances or unsatisfactory conditions.

- Have direct access to responsible management levels where appropriate action can be effected.

\subsubsection{Program}

The QA program is designed to assure the quality and reliability of HWHF activities and that activities are planned, controlled, implemented, maintained, and documented in accordance with the NQA-1-1989 standard.

\subsubsection{Design Control}

The design and construction of new facilities and the modification of existing facilities are performed in accordance with the design criteria specified in DOE Order $6430.1 \mathrm{~A}[19]$. 


\subsubsection{Procurement Document Control}

Quality-affecting procurement documents are controlled to assure that the procurement cycle has been implemented effectively.

\subsubsection{Instructions, Procedures, and Drawings}

Instructions, procedures, and drawings are prepared for each quality-affecting activity to the level of detail necessary to assure that the activity can be performed as required. Waste Management Program procedures are listed in Appendix A.

\subsubsection{Document Control}

The Operations Unit is responsible for document preparation, review, approval, revision, control, and distribution of documents related to waste disposal operations. Controlled documents include, but are not limited to, the Waste Management QAIMP and implementing procedures.

\subsubsection{Control of Purchased Items and Services}

Procurement and Work Order Requests are used to assure that materials, equipment, and services important to the EH\&S activities are procured to meet specific requirements.

\subsubsection{Identification and Control of Items}

Waste containers, waste samples, and disposal activities are controlled in a manner designed to provide unique container identification, unique sample identification, and tracking and labeling of waste. Procedures governing these activities are listed in Appendix A. 


\subsubsection{Control of Processes}

Waste-handling activities are performed in accordance with procedures specified in the Waste Management Plan [6] and related implementing procedures. Waste certification is controlled by the applicable waste certification plan requirements.

\subsubsection{Inspection}

Inspections are conducted to verify waste characterization, container adequacy and packaging, and the correctness of records. Procedures for inspection include standards of acceptance and rejection in the form of checklists.

\subsubsection{Test Control}

Tests are performed by the HWHF to verify performance of treatment processes and characterization of waste, and to demonstrate container and packaging adequacy. Tests are performed according to the DOT regulations and WHC-WAC.

\subsubsection{Control of Measuring and Test Equipment}

Measuring and test equipment used in the waste certification process is calibrated on a schedule recommended by the vendor. In addition, calibration (operational readiness) checks are performed by analysts and technicians before instruments are used. Calibration tags or stickers are attached to instruments and equipment to indicate the last calibration date and the next due date.

All measuring and test equipment will be certified against equipment having known valid relationships to nationally recognized standards, such as the National Institute for Standards and Technology.

Instrument and equipment calibration procedures and records are maintained by the EH\&S Division. The Environment Department Manager approves the development and use of calibration procedures and requirements for control of measuring and test equipment for LLW. 


\subsubsection{Handling, Storage, and Shipping}

The handling, storage, and shipping of LLW is accomplished in accordance with procedures and instruction specified in the Waste Management Program procedures listed in Appendix A.

\subsubsection{Inspection, Test, and Operating Status}

The inspection, test, and operating status indicators used are in accordance with the requirements specified in the relevant procedures.

\subsubsection{Control of Nonconforming Items}

Nonconforming items can be out-of-specification waste containers, imperfect or malfunctioning test and measurement devices, or other out-of-specification or noncompliance items that could adversely affect waste certification, handling, transportation, or disposal. Items in the HWHF that are identified as nonconforming are segregated and marked until corrected or properly dispositioned (i.e., waste containers that do not meet approved standards, waste that cannot be accepted by the WHC, etc.), as detailed in EH\&S Procedure 808, Nonconformance and Corrective Action Control.

\subsubsection{Corrective Action}

The HWHF staff is responsible for taking prompt and appropriate action to prevent the effects of a detected quality problem from spreading. The attendant HWHF staff person notifies the Operations Manager and others whose work is affected, and documents the problem and the corrective action taken when any of the following apply:

- An approved documentation QA record is changed because of the problem or will be by the corrective action taken;

- The problem is not trivial, and there is a significant probability that it will reoccur, or 
- A written agreement (maintenance agreement, vendor specifications, etc.) related to HWHF work, cost, or schedule is affected by the problem or correction.

\subsubsection{Certification Records}

In general, QA records are retained for the lifetime of the HWHF; however, the Environment Department Manager may limit or extend the retention period and may specify methods of disposal.

\subsubsection{Surveillance and Audits}

In accordance with the LBL IQAPP, all divisions are audited on a rotating basis within a two- to three-year period.

\subsection{QA Program Index}

In compliance with Department of Energy Order 5700.6C [17], WM has selected ASME NQA-1-1989 as the national consensus standard basis of its QA program. Table 4-1 identifies the NQA-1 criteria and the relevant WM QAIMP sections. 
Table 4-1. NQA-1 Criteria and Relevant WM QAIMP Sections

\begin{tabular}{|c|c|c|c|c|c|c|c|c|c|c|c|}
\hline & \multirow[b]{2}{*}{ NQA 1 Criterion } & \multicolumn{10}{|c|}{ WM QAIMP Criterion } \\
\hline & & 1 & 2 & 3 & 4 & 5 & 6 & 7 & 8 & 9 & 10 \\
\hline 1 & Organization & $\bar{V}$ & & & & & & & & $\sqrt{ }$ & \\
\hline 2 & $\begin{array}{l}\text { Quality Assurance } \\
\text { Program }\end{array}$ & $\boldsymbol{v}$ & $\checkmark$ & & & & & & & & \\
\hline 3 & Design Control & & & & & & $V^{*}$ & & & & \\
\hline 4 & $\begin{array}{l}\text { Procurement } \\
\text { Document Control }\end{array}$ & & & & & & & $\sim$ & & & \\
\hline 5 & $\begin{array}{l}\text { Instructions, } \\
\text { Procedures, \& Dwgs. }\end{array}$ & & & & & $\boldsymbol{v}$ & & & & & \\
\hline 6 & Document Control & & & & 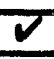 & & & & & & \\
\hline 7 & Purchasing Control & & & & & & & $\bar{v}$ & & & \\
\hline 8 & ID and Control & & & & & $\boldsymbol{v}$ & & & & & \\
\hline 9 & Special Processes & & $\checkmark$ & & & $\bar{v}$ & & & & & \\
\hline 10 & Inspection & & $\bar{\square}$ & & & & & & $\boldsymbol{V}$ & & \\
\hline 11 & Test Control & & & & & & & & $\bar{V}$ & & \\
\hline & $\begin{array}{l}\text { Measuring and Test } \\
\text { Equipment }\end{array}$ & & & & & $\checkmark$ & & & & & \\
\hline & $\begin{array}{l}\text { Handling, Shipping, } \\
\text { and Storage }\end{array}$ & & & & & $\boldsymbol{v}$ & & & & & \\
\hline & $\begin{array}{l}\text { Inspection, Test, and Ops } \\
\text { Status }\end{array}$ & & & & & & & & $\boldsymbol{c}$ & & \\
\hline 15 & Nonconformances & & & $\checkmark$ & & & & & & & \\
\hline 16 & Corrective Action & & & $\bar{\sigma}$ & & & & & & & \\
\hline & Records & & & & $\checkmark$ & & & & & & \\
\hline 18 & Audits & & $\checkmark$ & & & & & & & & $\checkmark$ \\
\hline
\end{tabular}

*Design control measures do not apply to the Waste Management Program. 


\section{Section 5: References}

1. Westinghouse Hanford Company (1991), Hanford Site Radioactive Solid Waste Acceptance Criteria, Richland, WA, WHC-EP-0063-3.

2. Washington State (1991), Dangerous Waste Regulations, Chapter 173-303, Washington Administrative Code, Washington State Department of Ecology, Olympia, WA.

3. Lawrence Berkeley Laboratory (1991), Draft Radioactive Mixed Waste Certification Plan, Lawrence Berkeley Laboratory, Berkeley, CA.

4. Department of Energy (1988), Radioactive Waste Management, U.S. Department of Energy, Washington, D.C., DOE Order 5820.2A.

5. Lawrence Berkeley Laboratory (1991), Draft Transuranic Waste Certification Plan, Lawrence Berkeley Laboratory, Berkeley, CA.

6. Lawrence Berkeley Laboratory (1991), Draft Waste Management Plan, Lawrence Berkeley Laboratory, Berkeley, CA.

7. Environmental Protection Agency (1991), Environment, Code of Federal Regulations Title 40, Washington, DC.

8. Department of Transportation (1991), Transportation, Code of Federal Regulations, Title 49, Washington, D.C.

9. State of California (1991), Toxics, California Administrative Code, Title 26, California Code of Regulations, Sacramento, CA.

10. Lawrence Berkeley Laboratory (1990), Health and Safety Manual, UC Berkeley, CA, PUB-3000.

11. Lawrence Berkeley Laboratory (1991), Guidelines for Generators of Hazardous Chemical Waste at LBL and Guideunes for Generators of Radioactive and Mixed Waste at $L B L$, Lawrence Berkeley Laboratory, Berkeley, CA.

12. Lawrence Berkeley Laboratory (1991), Waste Minimization and Pollution Prevention Awareness Plan, Lawrence Berkeley Laboratory, Berkeley, CA.

13. Lawrence Berkeley Laboratory (1992), Quality Assurance Implementing Management Plan, Lawrence Berkeley Laboratory, Berkeley, CA.

14. Lawrence Berkeley Laboratory (1991), Waste Analysis Plan, Hazardous Waste Handling Facility, LBL, Lawrence Berkeley Laboratory, Berkeley, CA.

15. State of California (1991), California Health and Safety Code, Division 17, California Code of Regulations, Sacramento, CA. 
16. Nuclear Regulatory Commission (1991), Energy, Title 10, Code of Federal Regulations, Washington, DC.

17. American Society for Testing and Materials (1984), Standard Test Method for Surface Burning Characteristics of Building Materials, ASTM Standard E-84-84a, Philadelphia, PA.

18. Department of Energy (1991), Quality Assurance, U.S. Department of Energy, Washington, D.C., DOE Order 5700.6C

19. Department of Energy (1989), General Design Criteria, U.S. Department of Energy, Washington, D.C., DOE Order 6430.1A. 


\section{Appendix A \\ MASTER PROCEDURE LIST WASTE MANAGEMENT PROGRAM}

Procedure \# $\quad$ Short Title $\quad$ Old \# (if changed)

\section{0-819: General, Vendor Oversight, Quality Control}

800

802

803

804

805

808

810

811

812

813

814

815

818
General Policy Statement (Rev. 1, 3/20/92)

Waste Management Documentation and Guides (Rev. 1, 9/22/92)

Document Control (Rev. 1, 9/22/92)

Records Management (Rev. 1, 9/22/92)

Procedure for Writing Procedures (Rev. 0, 7/17/91)

Nonconformance Control (Rev. 0, 6/3/92)

General Vendor Oversight Policy Statement (Rev. 0, 7/17/91)

Oversight Procedures-Onsite Transportation (Draft, 1/92)*

Oversight Procedures-Lab Packing (Rev. 1, 3/20/92)

Control of Measuring and Test Equipment (Rev. 1, 9/22/92)

Internal Audits and Quality Surveillances (Rev. 1, 9/22/92)

Management Reviews (Self-Assessments) (Rev. 1, 9/22/92)

Waste Management Training Program Plan (Rev. 1, 9/22/92)

820-825: Work procedures applying to both hazardous and rad waste

820

820.1

821

822

823

\section{6-859: Procedures applying to radioactive and mixed waste only}

826

827

828

829

830

831

831.1

833

835

840

841

842
Characterization Procedure (Rev. 0, 5/27/92)

Hazard Categorization (Draft, 7/92)

Sampling Procedure (Draft, 7/92)

Container Procurement, Receipt, and Control (Draft, 1/92)

Transfer of Waste from Inadequate Drums (Draft, 6/92)
Onsite Transportation of Radioactive Waste (Rev. 1, 9/22/92)

Offsite Transfer of Radioactive Waste (Rev. 1, 9/22/92)

Radwaste Tracking (Rev. 0, 6/15/92)

SDARs (Rev. 0, 6/15/92)

Radwaste Documentation/Release Procedures for Shipments to Hanford Burial Site (Rev. 0, 5/27/92)

Instructions on Filling Out SWS/DRs (Rev. 0, 6/15/92)

Labeling/Characterization/Segregation of Stored Radwaste (Draft, 1/92)

Storage/Inspection of Radwaste at HWHF (Draft, 7/92)

Compaction of Solid Low-Level Radioactive Waste (Rev. 1, 6/15/92)

Packaging of Noncompacted Solid Low-Level Radioactive Waste (Rev. 0, 6/15/92)

Packaging of Noncompacted Solid Low-Level Radioactive Waste-
806

806.1

816

807

817

809.1 Wooden Boxes (Rev. 0, 6/15/92)

* Final version awaiting Part B Permit approval.

NOTE: All procedures have been implemented; procedures implemented in draft form are still undergoing independent review or field testing. 


\section{Appendix A (continued)}

\section{MASTER PROCEDURE LIST \\ WASTE MANAGEMENT PROGRAM (p. 2)}

Procedure\# Short Title Old \# (if changed)

Packing of Induced Metals, Materials, and Equipment (Rev. 0, 6/15/92)

Packing of Low-Level Absorbed Tritium (Rev. 0, 6/15/92)

Scintillation Vial Crushing (Rev. 1, 9/22/92)

847

Solidification of Low-Level Radioactive Waste Liquid

(Rev. 1, 6/15/92)

848 Consolidation Procedure - Low-Level Radioactive Mixed Waste (Draft, 6/92)

855 Packaging of Transuranic Radioactive Waste (Draft, 6/92)

\section{0-889: Procedures applying to hazardous waste only}

$861 \quad$ Manifesting and Shipping (Rev. 1, 5/27/92)

862

863

865

867

868

868.1

Waste Container Request, Issuance, and Control (Draft, 1/92) Inspections (Draft, 1/92)

Consolidation Procedure (Rev. 0, 2/20/92)

Hazwaste Tracking (Rev. 0, 5/27/92)

Release of RCRA/TSCA Waste from Uncontrolled Areas (Rev. 0, 5/27/92)

Release of RCRA/TSCA Waste (unknown origin) from HWHF (Rev. 0, 5/27/92)

Release of Materials/Equipment from RMMAs (Rev. 0, 5/27/92)]

878 Handling of Bulk Coolants (Draft, 1/92)*

879 Organic Liquids-Flammable (Draft, 1/92)*

880 Organic Liquids-Halogenated Solvents (Draft, 1/92)*

881 Consolidation of Asbestos (Draft, 1/92)*

882 Consolidation of Contaminated Soil (Draft, 1/92)*

\section{0-899: Emergency Procedures}

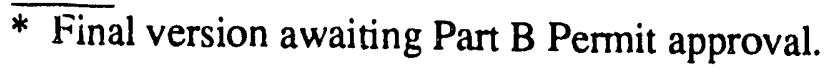




\section{Appendix B}

\section{Definitions}

Dangerous Wastes: Those solid wastes designated in WAC 173-303-070 through 173303-103 (Washington State 1989) as dangerous or extremely hazardous waste. As used in this chapter, the words "dangerous waste" will refer to the full universe of wastes regulated by this chapter (including dangerous and extremely hazardous waste). (See also "extremely hazardous waste" and "hazardous waste" definitions).

Extremely Hazardous Waste: Those dangerous wastes designated in WAC 173-303-070 through 173-303-103 (Washington State 1989) as extremely hazardous. (See also "dangerous waste" and "hazardous waste" definitions).

Hazardous Wastes: Those solid wastes designated by 40 CFR Part 261, and regulated as hazardous waste by the United States EPA. (See also "dangerous" and "extremely hazardous waste" definitions).

Low-Level Waste: Waste that contains radioactivity and is not classified as high level waste, TRU waste, spent nuclear fuel, or by-product material as defined in DOE Orders $5820.2 \mathrm{~A}$ and 5400.3 . Test specimens of fissionable material irradiated for research and development only, and not for the production of power or plutonium, may be designated as $\mathrm{LLW}$, provided the concentration of TRU radionuclides is $\leq 100 \mathrm{nCi} / \mathrm{g}$ of the waste matrix. The mass of the waste container must not be used in calculating the concentrations of radionuclides in the waste.

Badioactive Mixed Waste: Radioactive waste (LLW or TRU waste) that is co-contaminated with dangerous waste as defined in WAC 173-303-040(18) (Washington State 1989).

Transuranic Waste: Without regard to source or form, TRU waste is waste contaminated with alpha-emitting TRU radionuclides with half-lives $>20$ yr and concentrations $>100$ $\mathrm{nCi} / \mathrm{g}$ of the waste matrix. Transuranic radionuclides are radionuclides having an atomic number $>92$. In addition to TRU radionuclides, radium sources and $233 \mathrm{U}$ in concentrations $>100 \mathrm{nCi} / \mathrm{g}$ of the waste matrix are designated as TRU waste by Westinghouse Hanford because of hazards similar to TRU waste. The concentration limit $(100 \mathrm{nCi} / \mathrm{g}$ of waste matrix) for TRU waste applies to the item at the time it is declared waste. Additional processing of the waste (e.g., grouting) cannot be used to dilute the concentration of the fissile material and thereby change its waste designation. The only acceptable methods to be used in reducing the concentration of fissile material in waste packages are approved, permitted decontamination or treatment processes. The mass of the waste container must not be used in calculating the specific activity of the waste.

Packaged TRU waste with a surface dose rate that does not exceed $200 \mathrm{mrem} / \mathrm{h}$ is designated as contact-handled TRU. Packaged TRU waste with an external dose rate in excess of $200 \mathrm{mrem} / \mathrm{h}$ is designated as remote-handled TRU. Radioactive waste with quantities of TRU radionuclides in concentrations of $100 \mathrm{nCi} / \mathrm{g}$ of the waste matrix or less is $L L W$. 

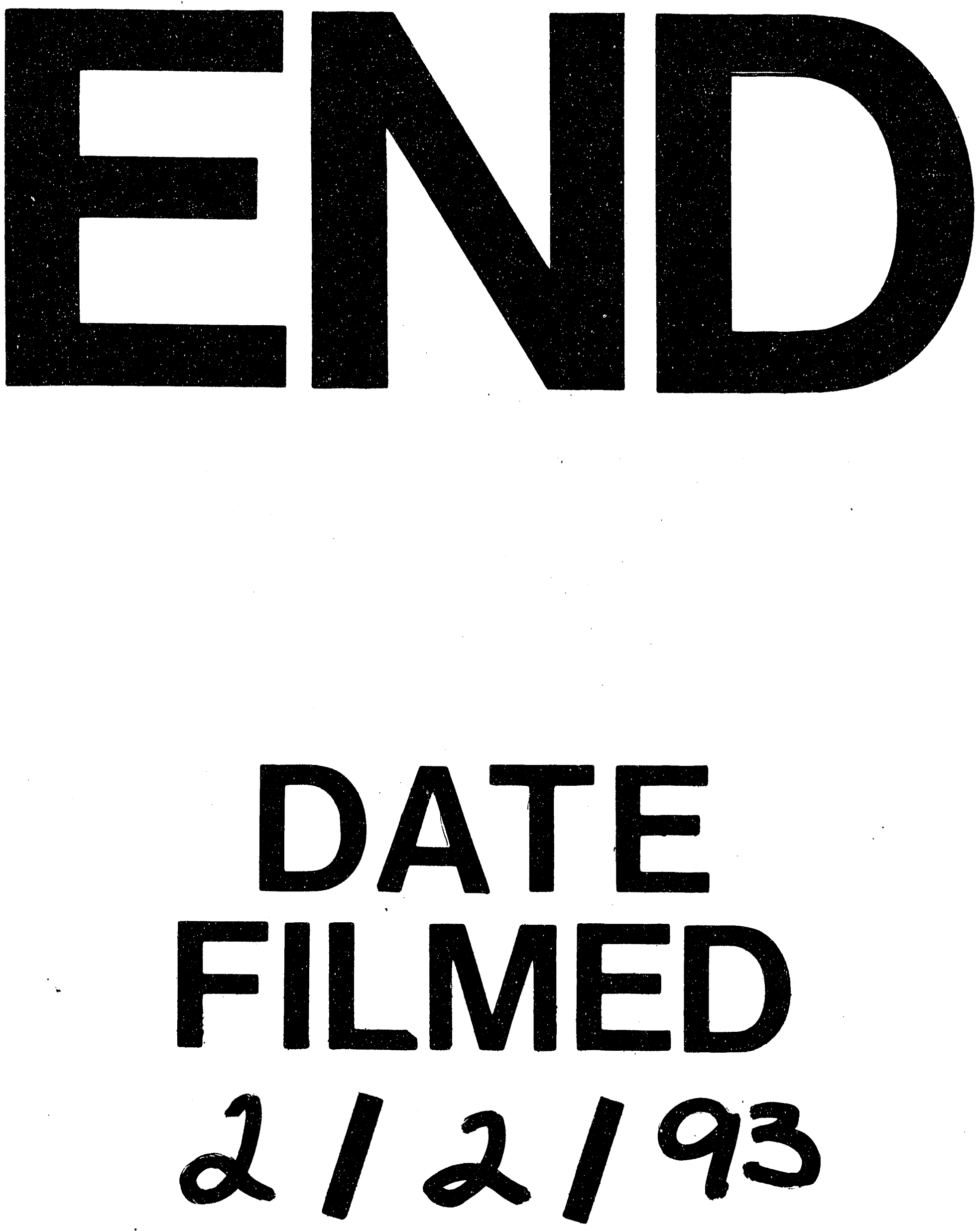
